Portland State University

PDXScholar

\title{
An Assessment of the Incorporation of Established Guidelines and Intercultural Communication Concepts into U.S. College-Sponsored Study Abroad Programs
}

Thomas Thaxter Bacheller IV

Portland State University

Follow this and additional works at: https://pdxscholar.library.pdx.edu/open_access_etds

Part of the International and Comparative Education Commons, and the International and Intercultural Communication Commons

Let us know how access to this document benefits you.

\section{Recommended Citation}

Bacheller, Thomas Thaxter IV, "An Assessment of the Incorporation of Established Guidelines and Intercultural Communication Concepts into U.S. College-Sponsored Study Abroad Programs" (1985). Dissertations and Theses. Paper 3425.

https://doi.org/10.15760/etd.5303

This Thesis is brought to you for free and open access. It has been accepted for inclusion in Dissertations and Theses by an authorized administrator of PDXScholar. Please contact us if we can make this document more accessible: pdxscholar@pdx.edu. 
AN ABSTRACT OF THE THESIS OF Thomas Thaxter Bachelier for the Master of Arts in Speech presented July 15, 1985.

Title: An Assessement of the Incorporation of Established Guidelines and Intercultural Communication Concepts Into U.S. College-Sponsored Study Abroad Programs.

APPROVED BY MEMBERS OF THIS THESIS COMMITTEE:
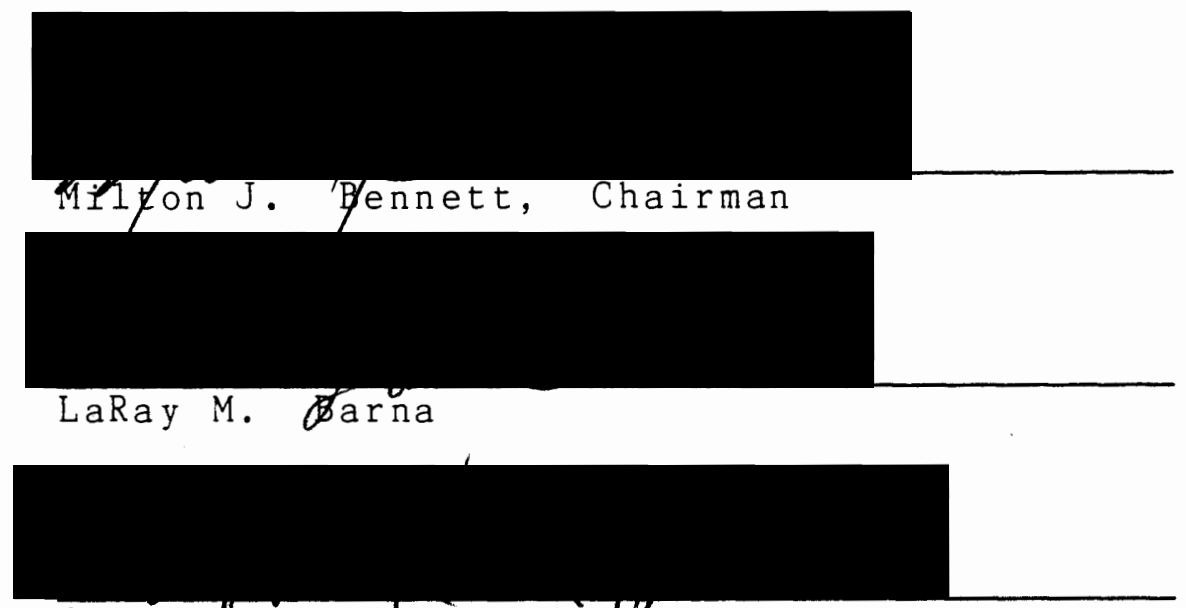

Stephed A. Kbsokof OC

This research project had the following goals:

1) To locate, describe, and synthesize recognized authoritative standards of performance and guiding principles of effective good practice for study abroad programs that have been established, endorsed, and supported by professionals and national organizations in the study abroad field.

2) To review selected literature on intercultural communication that has been published in the last fifteen 
years and examine intercultural communication theories and strategies applicable to the study abroad field to identify aspects which can most clearly benefit the study abroad experience of a sojourner through improved communication competence.

3) To assess the extent to which study abroad institutions or programs are operating according to the principles and standards of good practice specified by the professionals and national organizations in the study abroad field, and to discover how important study abroad program administrators feel these principles and standards are for their programs. 4) To assess the degree to which study abroad institutions or programs are incorporating relevant intercultural communication training into their study programs abroad. After reviewing literature from professional organizations concerned with study abroad and literature on intercultural communication, a questionnaire was developed. This questionnaire was developed primarily from the recurring themes extracted from the professional organizations publications and intercultural communication concepts relevant to study abroad. There were 68 questions covering four important areas of study abroad. These areas were: Goals and objectives, Cross-cultural involvement, Orientation and Program evaluation.

The questionnaire was mailed to a random sample of 200 study abroad program directors nationwide. 115 usable 
questionnaires were returned. The data collected reveals some of the prevailing practices in the study abroad field in these areas. This was a descriptive research project and consequently the data is presented with descriptive measures of central tendency.

A reliability study was conducted to test the reliability of the survey instrument. This was done by administering a second questionnaire to a subset of respondents. Pearson product-moment correlation coefficents were computed for all questions employing likert-type scales, and for the questionnaire as a whole. Most questions were found to be very reliable, and the questionnaire as a whole was found to be significant in reliability at the $p<.001$ level.

This research project has shown that in general, study abroad program administrators agree with professional study abroad organizations regarding what aspects are important to include in their programs. In most cases guidelines are not being implemented to as great a degree as program directors would like. Program directors do not find re-entry orientation programs nearly as important as professiona 1 organizations do. The extent to which intercultural communication concepts are included in study abroad programs varied widely. Most intercultural communication concepts inquired about are being incorporated into study abroad programs to some degree. 
AN ASSESSMENT OF THE INCORPORATION OF ESTABLISHED GUIDELINES AND INTERCULTURAL COMMUNICATION CONCEPTS INTO U.S. COLLEGE-SPONSORED STUDY ABROAD PROGRAMS

by

THOMAS T. BACHELLER IV

A thesis submitted in partial fulfillment of the requirements for the degree of

MASTER OF ARTS

in

SPEECH

Portland State University

1985 
TO THE OFFICE OF GRADUATE STUDIES AND RESEARCH:

The members of the Committee approve the thesis of Thomas Thaxter Bacheller presented July 15, 1985.

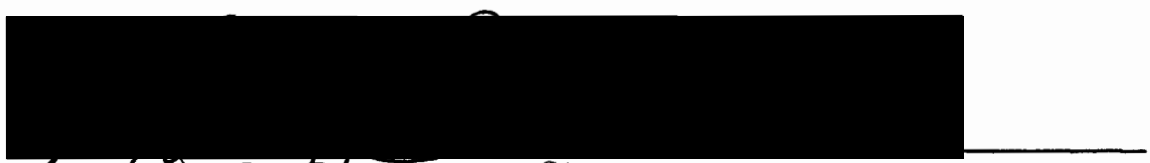

Miyton J. Befnnett, Chairman

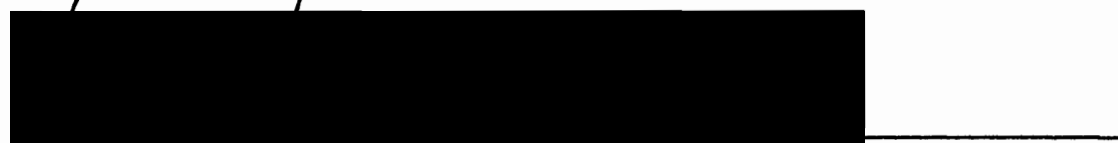

LaRay M. Bąha

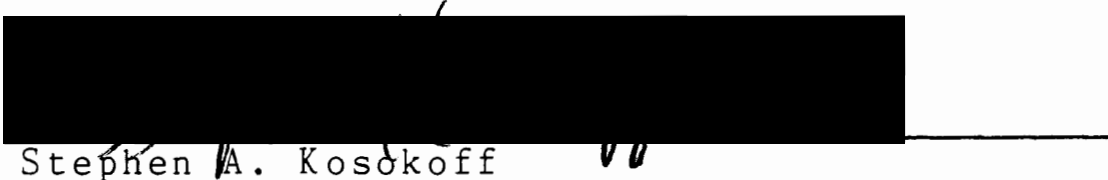

APPROVED :

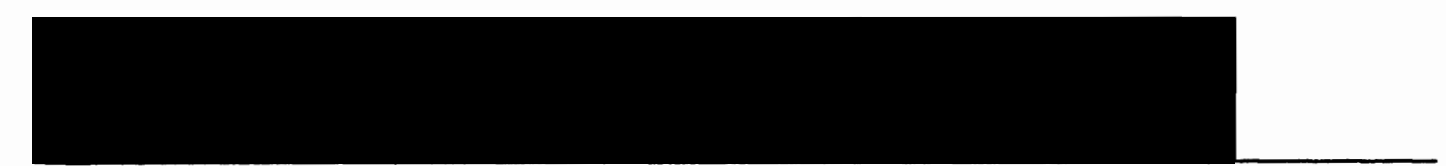

Theodore G. Grove, Head, Department of Speech

Jamés Heath, Dean of Graduate Studies and Research 
TABLE OF CONTENTS

PAGE

LIST OF TABLES

CHAPTER

I INTRODUCTION

History of study abroad . . . . . . . . . 1

Importance of study abroad . . . . . . . 3

Background to the study . . . . . . . . 4

The nature of the project . . . . . . . . 11

Research methods . . . . . . . . . 13

II REVIEW OF LITERATURE . . . . . . . . . . . 17

NAFSA introduction . . . . . . . . . 19

ANTFOSA Guide . . . . . . . . . . . 21

NAFSA Principles . . . . . . . . . . 27

NAFSA Standards \& Responsibilities . . . . 31

NAFSA Handbook . . . . . . . . . . 33

The CIEE Guide . . . . . . . . . . . 40

The CIEE Project . . . . . . . . . 4 46

Accreditation Handbook . . . . . . . 49

Summary of professional literature . . . . 51

Review of intercultural communication concepts relevant to study abroad . . . . . . . 53

Summary . . . . . . . . . . 68 
CHAPTER

II METHODS $\quad$ • • • • • • • • • • • • • • • • 70

Creation of the survey instrument . . . . 70

Origins of the survey questions . . • • • 72

The respondent selection process . . . . 82

The survey procedure • . . . . . . 85

IV PRESENTATION OF DATA . . . . . . . . . . 88

$\mathrm{V}$ IMPLICATIONS, LIMITATIONS, DISTORTIONS,

RELIABILITY STUDY AND SUMMARY • • • • • • • • 108

Discussion of implications . . • . . . . 108

Limitations of the study . . . . . . . 115

Possible distortions of information . . . 117

Reliability study . . . . . . . . . . 118 .

Implications for future research . . . . . 121

Summary and conclusions . • . . . . . . 122

SELECTED BIBLIOGRAPHY . . . . . . . . . . . . 123

APPENDIX A . . . . . . . . . . . . . . . 128

APPENDIX B . . . . . . . . . . . . . . . . . 135

APPENDIX C . . . • . . . • . . . . . . . . . . 136

APPENDIX D . . . . . . . . . . . . . . . . 137 


\section{LIST OF TABLES}

TABLE

PAGE

IV A Number of responses and percent of total responses for question one . . . . . . . 89

IVB Mean ratings of goals and objectives for

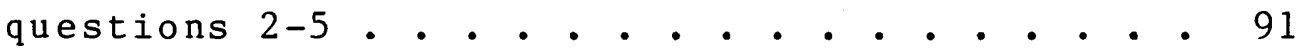

IV C Mean ratings of goals and objectives $6 \mathrm{~A}-\mathrm{J}$. • 92

IV D Mean ratings of 1955 goals of sponsoring

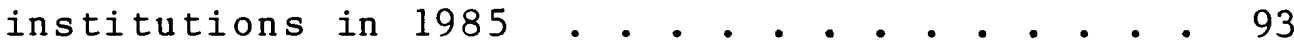

IV E Mean ratings of section II . . . . • • . . . 95

IV $F$ Number of responses and percent of total responses for question three... . . . . 96

IV G What forms orientation programs take • • • • 97

IV $H$ Who of the following are utilized as orientation resources . • • • • • . • • . 98

IV I Teaching methods utilized in orientation

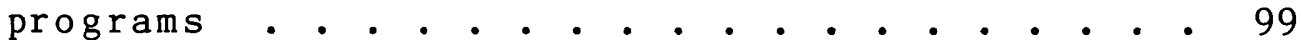

IV $J$ Mean scores for intercultural communication

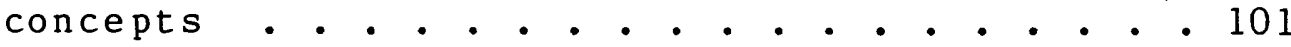

IV $\mathrm{K}$ Mean scores for re-entry problems . . . . . 103

IV L Provisions made for program evaluation . • • 104

IV M Program aspects evaluations focus on . . • . 105

IV $\mathrm{N}$ When program evaluations are done . • • • • 106 
TABLE

V A Mean ratings of 1955 goals of sponsoring institutions in 1985 . . . . . . . . . . 110

$V$ B Mean ratings of highest rated goals and objectives . . . . . . . . . . . . . 110 


\section{INT RODUCTION}

\section{HISTORY OF STUDY ABROAD}

The practice of journeying to a foreign country for educational purposes dates back to the time of ancient Greece. It was then that students of the ancient world first went to Athens to study, cutting across cultural, geographic and national boundaries. As early as the 4 th century B.C. groups of foreign students were attending the Greek schools of rhetoric and philosophy. By the 4 th century A.D. the Theosodosian Code had to include special provisions dealing with the admission of foreign students and their eventual return home, because of the political and administrative problems caused by the large number of foreign students flocking to Rome (Walden, 1909).

By the year 639 A.D. the emperor of China had established an institution of higher education to which students from the 'barbarian peoples' came until there were 8,000 of these foreign students in attendence (Mandelbaum, $1956, \mathrm{p} .45)$.

Study abroad assumed particular significance in connection with the foundation of the first European universities in the 12 th century A.D. These 'universitates 
magistrorum et scholarum' i.e., communities of teachers and pupils engaged in joint 'general studies', developed largely from the guilds of wandering scholars, protective associations of foreign students who formed the actual nuclei of the medieval universities (Haskins, 1923).

The idea of attending school in different countries became recognized as essential for discovering new knowledge and truth, and enriching the human experience. 0niy recent1y however, has study abroad had a significant impact on higher education in the United States (Marion, 1974).

In the $19 t h$ and 20 th centuries a handful of American graduate students attended the great European universities, but until the onset of junior year abroad programs in the 1920 's, few undergraduates crossed the oceans in pursuit of an international education.

In 1945 the United Nations Educationa1, Scientific, and Cultural Organization (UNESCO) was founded. This event is claimed by some to be the genesis of modern international education (Carroll, 1974). After the Second World War American colleges and universities began to rapidly increase the number of programs overseas that were designed explicitly for academic purposes. In 1956 only 1,000 American students studied abroad. By 1968 the number of American students abroad increased to roughly 10,000 in over 300 programs. Enrollment in study abroad programs continues to increase today, even though a national recession 
prevails. The number and variety of overseas programs are a surprise to most people today. In 1976 there were an estimated 1,300 study abroad programs available to American students (Bowman, 1980).

THE IMPORTANCE OF STUDY ABROAD IN TODAY'S GLOBAL VILLAGE

In the last part of this century the realization that citizens of all nations are citizens of the same "global village" has become increasingly salient. The time is here when many peoples of our planet are accepting the reality of global interdependence. Even the United States with its "super power" status finds itself interdependent with weaker nations who happen to possess certain natural resources required to keep our highly industrialized nation moving. Other important global issues facing all nations include preservation of the earth's environment, stabilizing the world economy, world poverty and hunger and of course the ultimate threat to all of mankind; nuclear war.

Many experts feel that if international educationa 1 interchange is not utilized to help achieve an understanding of these issues which threaten all mankind, the cooperative effort required to find the necessary solutions to these problems may never be actualized (NAFSA, 1980). If mutually agreeable solutions are not found, the future of our "global village" is at best uncertain. Consequently, it is of utmost importance to the very survival of mankind for each 
of us to become better informed about other peoples, cultures and their inherent interrelationships. One of the main goals of modern liberal education should thus be to provide students with the op portunities to acquire this basic knowledge. For this reason, among others, international education recieves high priority among today's colleges and universities.

\section{BACKGROUND TO THE STUDY}

"One can see that international education has evolved in a slow but steady way. One can also see that the process is nowhere near complete" (Carrol1, 1974).

The number of U.S. colleges which sponsor study programs abroad has increased dramatically since the end of World War II. International education has today become an essential part of U.S. higher education. However, the rapid growth of study abroad programs has not been without its problems. Programs have been developing largely in isolation from one another because of a lack of any real theoretical framework by which to structure programs and policies. Many programs have been created and run primarily on a trial and error basis. Individual institutions left to chance the development, refinement, operation and evaluation of their programs. In many cases this led to poor quality programs and equally poor integration of study abroad programs into the sponsoring 
college or university. Many overseas programs were allowed to develop largely unchecked because they originated as a result of the enthusiasm, imagination and dedication of a single person. In many cases the administration of the home institution was more than content to let this pioneer actualize his own vision and "do his thing" (Abrams \& Heller, 1978).

An ot he r reas on poor 1 y planned ventures have proliferated in the study abroad field is that these popular programs have traditionally been regarded as unquestioningly good, due to their increasing numbers, and their success has too often been measured by the standard of growing enrol1ments ( $J$. Bennett, 1984).

In the 1950's concern with the improvement of study abroad programs increased. Educators were seeing the need for improving overseas academic programs to make them of comparable quality to academic programs in our own country. This need stemmed in part from students' increasing inquiries about receiving academic credit on their home campus for foreign study experiences.

Another concern was about organizers who set up study abroad programs labelled as "educational", which in reality lacked sound educational planning, and served primarily to financially exploit the involved students.

Concerns with these and other related problems led a new ly formed group, the Council on Student Travel to 
pursue the topic of "improving overseas programs" at their annual conferences in the 1950's. Their concern with raising standards in the operation of overseas student programs lead to several other seminars and laid the foundation for future publications.

Educators continued to approach these problems in the $1960^{\prime}$ s by addressing them during several professional conferences and seminars. In 1961 a series of conferences on "Undergraduate Study Abroad" was sponsored cooperatively by the Association of American Colleges, the Council on Student Travel, the Institute of International Education and the Experiment in International Living. That same year the Carnegie corporation sponsored a conference dealing with standards for college-sponsored summer programs abroad. In 1962 The National Committee of Regional Accrediting Agencies adopted a statement on overseas study programs.

A small handful of publications were published which dealt to some degree with the improvement of study programs abroad. Several of these will be discussed in detail in chapter two as they were used extensively in this research project.

Since World War II when studying abroad became popular there have been many problems, and there has been some effort to remedy these problems. However, the literature on the subject is not easy to find. Much of it is today out of print, and even the organizations who sponsored the 
publications often can't tell you where to locate a copy. What material is available is often very basic, or vague and behind the times. Because available material has never been drawn together and synthesized into a unified framework, study abroad program administrators who wish to more clearly define what goals, objectives, standards and principles by which to operate their programs can be faced with a difficult task. Material designed to help program administrators effectively orientate their students has also not been drawn together very well.

After Wor 1d War II the wor $1 d$ was, at least in a figurative sense shrinking, and the realization that our world was indeed becoming a "global village" was beginning to change the way scholars thought about communication.

The modernization of transportation, along with sophisticated technica 1 innovations in long distance communications made close cultural contact a common occurrence. Today communication among people of various cultures and nations is quite normal. Coupled with this was a cultural revolution going on in our own country. Many subcultures including blacks, homosexuals, hippies and other groups were becoming more visible and vocal. It was soon found that it was difficult to communicate with these people, and our attempts were often unsuccessful. Americans became aware of the fact that there are true differences in speaking, gesturing, acting and even reasoning when 
communicating across cultural boundaries. This increased cultural contact with people different than mainstream Americans made it essential to begin trying to understand them so as to get along with them. Because culture has a major influence on the communication process the recognition of intercultural communication as a field of study emerged (Hoopes \& Pusch, 1981).

Communicating interculturally was not, of course, a post World War II phenomenon. It had been occurring ever since people from different cultures first encountered one another. What is new is the systematic study of what happens when these communicative interactions take place. Intercultural communication was born out of a fusion of ideas about culture, society, education, human psychology and communication theory. Intercultural communication emerged from a felt practical need. David S. Hoopes (1981) outlined these explicit needs well: 1) to train Americans to function more effectively abroad during the post World War II period when they were swarming overseas in vast numbers to live, work or study; 2) to aid in the adjustment of foreign students and trainees who began in the same era to come in large numbers to this country seeking the keys to industrial and technological development; and 3 ) to understand and manage the more explosive dimensions of inter-racial and inter-ethnic relations in the United States as the civil rights movement gained momentum in the early 
1960 's.

Intercultural communication as a discipline has on $1 \mathrm{y}$ recently begun to gain respect and acceptance into institutions of higher education. This began when "communication" began to break away from "speech communication", as a subject deserving special concern. Stephen W. Littlejohn (1983) calls the 1970's and 1980's the era in which the study of communication has come of age. Scholars primarily interested in communication are beginning to produce a great deal of research. Communication theories have been emerging as are journals, books, and departments of communication studies on our campuses.

The research into the nature of intercultural communication is diverse, and is spread thin through many fields such as anthropology, international relations, sociology, social psychology and psycholinguistics. Thus, al1 intercultural communication knowledge has not been well synthesized, or coordinated effectively with study abroad.

Knowledge of intercultural communication can aid in solving communication problems before they arise. The potential for intercultural communication to aid students studying in countries other than their own is becoming recognized. In a short period of time intercultural communication has made several valuable contributions which can be manifested in study abroad programming. Improved communication competence abroad has the potential to improve 
the sojourner's overall experience. Intercultural communication strategies do exist, and many of them can and perhaps should be used in study abroad programming. Consequently for this research project aspects of intercultural communication have been isolated which have the potential to benefit student sojourners. These aspects will be discussed in detail in chapter two. 
THE NATURE OF THE RESEARCH PROJECT

The project described in these pages has the following goals:

1) To locate, describe, and synthesize recognized authoritative standards of performance and guiding principles of effective good practice for study abroad programs that have been established, endorsed, and supported by professionals and national organizations in the study abroad field.

2) To review selected literature on intercultural communication that has been published in the last fifteen years and examine intercultural communication theories and strategies applicable to the study abroad field to identify aspects which can most clearly benefit the study abroad experience of a sojourner through improved communication competence.

3) To assess the extent to which study abroad institutions or programs are operating according to the principles and standards of good practice specified by the professionals and national organizations in the study abroad field, and to discover how important study abroad program administrators feel these principles and standards are for their programs.

4) To assess the degree to which study abroad institutions or programs are incorporating relevant intercultural 
communication training into their study programs abroad. 


\section{RESEARCH METHODS}

Guidelines were located from a variety of credible resources that specify what elements should be incorporated into high quality study abroad programs. The resources are summarized in chapter two. These guidelines were then synthesized and used to create an instrument used to survey the status quo of a random sample of study abroad programs nationwide.

The survey attempted to determine the extent to which international study programs are using the guiding principles and standards specified by respected professionals and organizations in the study abroad field, as well as how important program administrators feel these guidelines are for their programs. The survey also at tempted to assess the degree to which these schools are incorporating relevant intercultural communication training into their study abroad programs.

By doing a national survey of U.S. colleges and universities, I have been able to collect information on some of the prevailing practices in the field, and will attempt to paint a picture of the present state of affairs in these respects.

My intention is to keep this research on the descriptive level. I will not judge the data in an 
evaluative way. My goal is to systematically and objectively describe what is happening with these study abroad programs, and report on the trends and patterns $I$ see.

This study has the potential to make a valuable contribution to the study abroad field. An effort was made to find the most credible material that sets general guiding principles for high quality study abroad programs. This has never before been identified and synthesized. This material was then simplified into specific closed questions, with the answers providing data on existing conditions of study abroad programming. The hueristic value of this study is that after an accurate picture of the present state of affairs is complete, future research could evaluate prevailing trends, isolate problem areas, and suggest ways to improve them.

Study abroad programs are made up of many different and complex components. The survey created for this project deals with four of the most important areas involved with the administration of study programs abroad. The four areas researched in the survey that was conducted for this study are:
1) Goals and objectives
2) Cross-cultural involvement
3) Orientation
4) Program evaluation 
While reviewing the literature for this project a main goal was to create a comprehensive list of goals and objectives for study abroad programs. This was accomplished by reviewing literature dating back as far as 1955 published by professional organizations that concern themselves with the administration of study abroad programs. Clearly stating what the goals and objectives of a study abroad program are can in itself be a very good consciousness raiser for faculty and administrators. It is also important to have defined program goals and objectives, so students can attempt to match their own goals and objectives for going abroad with the goals and objectives of the program in question.

A third reason for clearly stating goals and objectives for study programs abroad is that there is an intimate tie with program evaluation. With the knowledge of what goals and objectives the program is hoping to accomplish, the program can be evaluated in that light. The evaluation can then point out where goals and objectives are not being met and improvements can be aimed at these deficiencies.

The other two areas of concern in this survey were cross-cultural involvement, and orientation training. I was curious to find out how important program administrators feel cross-cultural involvement is, and to what extent they structure their programs to encourage student participation 
in the host culture both academically and informally.

By looking into orientation training programs it was hoped to discover the degree to which these training programs are utilizing relevant intercultural communication concepts. Also if schools are doing any cultural training, when do they start this training, and how long do programs 1ast. Questions were also included dealing with re-entry orientation programs. 


\section{REVIEW OF LITERATURE}

The questions which comprised the questionnaire used in this research project were compiled through an extensive literature review. The literature reviewed was from two different yet complementary areas.

The first area reviewed was literature that has been published by professionals and national organizations that concern themselves with study abroad programming. These publications were examined in an attempt to locate recognized authoritative standards of performance and guiding principles of good practice for study abroad programs that have been established, endorsed and supported by these professionals and national organizations.

The second area was from the discipline of intercultural communication. Intercultural communication theories and strategies directed toward international education were examined in an attempt to identify aspects which can most clearly benefit the study abroad experience of student sojourners through improved communication competence.

In this chapter I will review the main bodies of literature from the first area which were used extensively 
when formulating the questions for this survey. After reviewing the literature published by professional organizations involved with study abroad, I will briefly synthesize the themes that recurred throughout the different publications. These recurrent themes were manifested into the survey instrument. Also reviewed will be the intercultural communication concepts which were used in this research project. In chapter three which addresses the creation of the survey instrument, I will be referring to these intercultural communication concepts, and the recurring themes from the professional organization's literature. 


\section{NAFSA INTRODUCTION}

The National Association for Foreign Student Affairs (NAFSA) provided much of the informational literature used in this study. NAFSA was formed in 1948 in response to the post-World War II surge in international educational exchange. The goal of this association was and still is to promote the professional development of individuals and organizations working in the field of international education. NAFSA is a nonprofit membership association that provides training, information and other educational services to professionals in this field.

The National Association for Foreign Student Affairs has grown to be the largest professional membership association that concerns itself with the administration of internationa 1 educational exchange. The 1985 membership is composed of over 5000 representatives of postsecondary institutions, school systems, community organizations, educational associations and individuals. Through its numerous publications, workshops, conferences and institutional consultations in the U.S. and abroad, the association serves as a reference for standards of performance, and as an advocate for the most effective operation of international educational exchange.

The association consists of five professiona 1 
sections. Much of the information used in this study stemmed from the publications of the section on U.S. Students Abroad (SECUSSA). SECUSSA's membership consists primarily of administrators, faculty and staff involved in the advising and administration of study programs for U.S. students abroad.

NAFSA's objectives as a professional organization are: 1) to assure that all individuals participating in international educational interchanges between the United States and other countries achieve the educational and personal goals envisioned for their sojourn in the United States;

2) to assure that those professional people who come in contact with participants in interchanges are guided by a firm belief in the worth, dignity and potential of every human being, regardless of national or ethnic origin, cultural or linguistic background, sex, race, social status, political affiliation or religious belief;

3) to assure that participants in educational interchanges learn as effectively and freely as possible, recognizing that the learning achieved in one culture is to be applied in others;

4) to promote the larger goals of educational interchanges, reflecting the increasing need for people of all countries to learn about one another and understand the conditions for interdependence. More specifically, the American people are 
urged to learn about the world and the ways in which it affects us, while people of other countries are expected to learn about us, our ways of 1 ife, and the ways in which our decisions and policies affect them.

\section{NAFSA (ANTFOSA) EVALUATION GUIDE}

In 1977 NAFSA established a task force called (ANTFOSA) to address the problem of evaluating study abroad programs. ANTFOSA was composed of three representatives from the Committee on Study Abroad by U.S. Students (SAUSS), of the American Association of Collegiate Registrars and Admissions Officers (AACRAO), three representatives from NAFSA's section on U.S. Students Abroad (SECUSSA), and James S. Frey as chairman.

ANTFOSA tested and refined an evaluation guide that was developed by James S. Frey to aid in the evaluation of study abroad programs. The result was a comprehensive evaluation instrument for use by program sponsors and/or evaluation teams. This evaluation instrument is presented in NAFSA's 1979 publication Study Abroad Programs: An Evaluation Guide.

The purpose of this guide is to identify strengths and weaknesses of individual study abroad programs. It is designed to identify improvements that should be made to make a program more effective and viable.

With this guide the major components of study abroad 
programs can be systematically analyzed by use of carefully phrased questions about each component. The components are classified under the following four headings:

A) Basic information

Printed materials

Objectives

Admissions requirements

B) Academic aspects

Curriculum

Faculty

Academic resources

C) Interaction with the host culture

Orientation

Cross-cultural involvement

D) Administrative aspects

Sponsoring institution or organization

Program administration

Affiliation with a host country institution

Housing and meals

Supportive services

Costs

Travel arrangement

For each question relating to these components sample answers are given which illustrate the most positive and negative responses. This provides the perimeters for evaluating each factor.

To complete a full evaluation using this guide, answers for each question are obtained from four different sources of information:

1) A review of all printed materials for the program

2) Program administrators

3) Current and former students

4) An on-site program review by an evaluation team 
From the answers of these four sources one composite answer is synthesized for each question. The composites are then compared to the sample positive and negative responses given in the guide. From the final composite answer strengths and weaknesses of each component are identified and summarized. Based on these findings recommendations are made for improvements that should be made in a study abroad program to make it more effective and viable. There are 87 in depth questions in the evaluation guide. They cover nearly everything that comprises a study abroad program, from the initial printed materials to the final program evaluation.

The NAFSA (ANTFOSA) Evaluation Guide is very detailed, and it proved to be a very valuable document in creating the survey instrument used in this study. Through the guide's systematic analysis of the major components of study abroad programs many general principles for international educational exchange could be extracted. These principles are what NAFSA's ANTFOSA task force believe are the substance of good practice in study abroad programming. Specific questions which were created as a result of this document will be discussed in chapter three.

This evaluation guide provided several important points which were used in my survey concerning goals and objectives in the administration of study abroad programs.

The ANTFOSA task force feels that the program's 
objectives should be made known to the students by stating them clearly in the printed material that is given to each prospective student. They also state that these objectives should also be discussed in detail during the orientation program.

One objective stated in this guide is that the curriculum should benefit from the host environment by making extensive and effective use of the unique physical, human and cultural resources offered there. These program resources should provide enrichment unattainable in the United States. The curriculum should be related to the program's stated objectives, and the content of the courses and the variety of experiences offered should be clearly sufficient to achieve these objectives.

The location of the program should provide ready access to the host country resources related to the program's curriculum and objectives.

The language requirements should be consistent with the program's objectives. Adequate language courses and facilities should be available.

The ANTFOSA task force thought that a main objective of study abroad programs should be to combine academic learning with cross-cultural learning experience, and to enrich undergraduate 1 earning by offering study opportunities which are not available in the United States. This guide also touched upon some concepts which were 
very helpful in the construction of the section in the survey which dealt with cross-cultural involvement.

They feel that programs should try to develop crosscultural understanding. This should be done by introducing students to an analysis of their own culture, and to an understanding of the host culture. This should be accomplished in orientation programs and through the curriculum, which should include courses which focus specifically upon the host culture. These courses should require involvement in the host culture through research assignments and field work.

The ANTFOSA task force feels it is important for programs to encourage informal out-of-class experiences which can have educational value. This can be done by arranging such things as housing, local transportation and social activities so they foster student involvement in the everyday activities of the members of the host culture. They feel this social interaction should be facilitated by the location of the program. Rather than isolate students from the host community, the location should provide frequent academic and social interaction in which students must communicate with persons from the host country and adjust to local customs and mores. They feel these informal contacts with persons from the host culture can provide meaningful learning experiences.

NAFSA feels all study abroad programs should provide 
some type of orientation. The Evaluation Guide provided some concepts in this area that was helpful for this research project.

The ANTFOSA task force feels that orientation programs should go beyond logistical matters such as instructions concerning payments, passports, visas and transportation arrangements. This task force feels orientation should begin before students leave the United States. Orientation programs should include reading lists, and discussion utilizing experienced faculty, staff, program alumi and citizens of the host country who are in the United States. They also feel orientation should continue upon arrival abroad. This part of the orientation should emphasize living and learning in the new environment.

Program evaluation is another area this guide dealt with. The ANTFOSA task force strongly feels that provisions should be made for program evaluation. To accomplish this they suggest that students, faculty and staff submit evaluations at the end of each term. The program should also make arrangements for periodic evaluation by an external agency. All evaluations should include a focus on academic and cultural aspects of the program. Suggested improvements that stem from these evaluations should be implemented where feasible. 
NAFSA PRINCIPLES FOR INTERNATIONAL EDUCATIONAL EXCHANGE

In 1981 the National Association for Foreign Student Affairs (NAFSA) published the NAFSA Principles for Internationa 1 Ed ucationa 1. Exchange. This comprehensive publication is a statement of useful, carefully honed standards and principles for international educational exchange which can help guide institutions and programs. The principles are designed to be believable, reasonable "standards" of good practice to bear in mind when creating, administrating or evaluating internationa 1 educationa 1 programs. They also apply to the delivery of advisory services. Professionals in the field and many national organizations support these principles. All institutional NAFSA members have been asked and encouraged to endorse these principles as a code of good practice. NAFSA suggests copies of the principles be distributed on campus to begin to raise awareness of important issues to those in leadership positions.

The NAFSA Principles are used as the basic document for institutional reviews of international educational programs on many campuses. If an institution is conducting a self-study the NAFSA Principles can be used to seek out obvious starting points for discussions, workgroup activities or as I used them as reaction items on survey instruments.

In 1983 NAFSA published a self-study guide which 
uses these principles as the main backdrop. The NAFSA Principles are divided into six main areas:

1) Principles for institutions

2) Principles for the admission of foreign students

3) Principles for English programs and determination of English proficency

4) Principles for foreign student/scholar services

5) Principlesforthe provision of community services and programs

6) Principles for U.S. study abroad

For my research purposes I incorporated two of these areas into the creation of my survey. The first was the Principles for institutions, and the second was Principles for U.S. study abroad.

I will briefly summarize the principles from these two areas.

\section{Principles for Institutions}

1) The institution should have a clearly stated policy about international educational exchange which sets forth the goals and objectives of the international educational program(s) developed by the institution.

2) The implications of the international educational policy for academic programs and academic staff should be discussed by the institution's executive staff, faculty and administrative staff.

3) Programs in international educational exchange should be 
closely related to and consistent with the basic purposes and strengths of the institution.

4) Regardless of program size, the institution should acknowledge its responsibility to demonstrate sensitivity to cultural needs. These factors must be accounted for in the planning and execution of the program.

5) Professionals who work in international educational exchange should be well trained and orientated to their particular responsibilities.

6) Administrative staff and faculty should seek to develop and maintain respect and sensitivity toward those from different cultures in the execution of their responsibilities for international educational exchange programs.

7) The institution should periodically evaluate programs, policies, and services in light of established goals, and regularly review those goals.

There are eleven principles stated for U.S. study abroad programs. Information on the principles is not intended to be prescriptive. The principles are merely suggestive of the kinds of issues, conditions and situations to be examined by program administrators if appropriate to the setting. I will breifly summarize the eleven principles from the study abroad section.

Principles for U.S. Study Abroad

1) Institutions should state a clear policy on their 
intentions and goals for facilitating study abroad.

2) There should be a central point of access to useful information about overseas opportunities.

3) Faculty and staff who are responsible for study abroad advising should be identified and 1 isted in campus reference literature.

4) Returning students should be asked to provide evaluations.

5) Printed program material should clearly state the purposes and educational objectives of the program

6) Accurate, honest, and complete information on all aspects of the program should be provided to prospective app1icants.

7) Applicants should be carefully screened.

8) Programs should include orientation, both predeparture and ongoing.

9) A. Programs should effectively use the unique physical, human, and cultural resources of the host environment. B. The academic rigor should be comparable to the home campus.

C. There should be clearly defined criteria for judging the students' academic performance, and assigning credit

10) Administrative arrangements should be managed effectively by qualified staff with appropriate experience.

11) Programs should be evaluated periodically, and changes made in light of the findings. 
NAFSA STANDARDS and RESPONSIBILITIES in

INTERNAT IONAL EDUCATIONAL INTERCHANGE

This NAFSA publication was first published in 1964 in response to the need for comprehensive guidance for establishing and maintaining programs in international student education. This statement was revised and adopted by the NAFSA board of directors in 1979. The guideline advocates a set of standards that will guide and direct the effective execution of responsibilities in international student exchange. The principles set forth in this book have been based on the experience and consensus of professionals who deal with foreign student affairs in the United States and abroad.

Several points that were made in this book were important to my study. The authors clearly state some standards and principles for non-formal education. They state: ..."informal, out-of-class experiences, if well planned and executed, can have high educational value in their own right, and should be encouraged as an integral part of an international education program." NAFSA feels that "incidental learning" obtained from non-classroom education is often as important to the individuals as traditional academic education. By increasing exposure to persons from other cultures non-formally, U.S. students can enrich their own educational experiences for their careers. Another factor has emerged that seems to indicate that 
adjustments are needed in the traditional thinking about the nature of cross-cultural educational experiences. Research and experiences continue to document that meaningful interpersonal contact with members of other countries and cultures can lead to understanding of social, educational, economic, cultural and political interactions and ultimately to improved international relations.

According to NAFSA several educational benefits U.S. students can receive through meaningful and sophisticated programs of intercultural exposure are:

1) Firsthand experiences in dealing with members of other cultures.

2) Development of skills in cross-cultural communication and relations needed to relate to people of other cultures, as well as to varied subcultural groups within the U.S.

3) Experiences in comparative thinking and analysis.

4) Understanding cultural dimensions of their fields of study

5) Realistic retrospect of how others see us which has a bearing on the future tasks and problems facing young Americans .

In this publication several principles were listed which were relevant to my study:

1) Universities and colleges should strive to create an atmosphere conducive to meaningful intercultural 
experiences for a 11 students.

2) Social activities should be balanced with a variety of other educational, cultural and intellectual programs.

3) Expected outcomes of participation in campus programs should be well defined and articulated.

4) Campus activities and programs should be conducted in accordance with principles of cultural sensitivity and prevailing university rules and standards of accountability.

5) The institution should regular1y provide meaningful training in leadership skills and dynamics of crosscultural groups whenever necessary.

6) Student programs should be evaluated against their stated objectives, especially where funds raised from others have been used in the programs.

STUDY ABROAD: HANDBOOK FOR ADVISERS AND ADMINISTRATORS

The final NAFSA document I reviewed for this project is entitled Study Abroad: Handbook for Advisers and Administrators. This guideline identifies good and poor practices, but it is basically descriptive rather than prescriptive. It is intended to be suggestive of policies, procedures and ways of dealing with problems that have worked for some institutions and can be adapted to the needs of others.

Chapter 7 which deals with the administration of study 
abroad programs starts with a brief list of what NAFSA feels are characteristics of good study abroad programs:

1) We11-defined academic objectives

2) Solid academic content, comparable to that on the home campus

3) Careful use of resources of the locale to create a unique educational experience not achievable on the home campus

4) A meaningful degree of cultural immersion and interaction with host country residents

5) Carefully selected, well oriented participants

6) Provisions for acquiring or improving language proficiency

7) High quality leadership

8) Affordable costs

9) Carefully planned logistics

10) A planned means for evaluating the program and making needed changes before it is repeated

This list of characteristics was important to this research project because several of these characteristics were used in the creation of the survey instrument.

I looked at this document primarily because it provided the clearest statement of all the NAFSA documents on orientation of participants, and evaluation of study abroad programs. I will first review the points from the orientation section that are applicable to this study. 
Orientation is defined here as the learning required for a person to function in a new situation. Orientation should be thought of as a process taking place over a long enough period of time to enable students to prepare themselves both mentally and emotionally to take optimum advantage of their study abroad opportunity. Orientation should encourage in-depth learning about the host country, the host country people and their culture.

Ideally orientation should begin soon after the students are selected. It should continue on a planned basis through the first few weeks after arrival at the study site abroad. There are several forms orientations can take. They include:

1) a series of weekly meetings held over a semester or academic year;

2) an orientation course for which credit is given;

3) a series of weekend workshops;

4) an intensive week-long workshop

However, if the participants are scattered from different campuses and cannot meet, an orientation handbook could be mailed out, or an intensive orientation session after arrival may be the on 1 y feasible alternatives.

This publication gives several ideas on who might serve as orientation resources. They include previous directors of the program, the current director, former student participants, foreign students and faculty from the 
host country and diplomats from the host country's embassy in Washington, D.C., if such visits can be arranged.

NAFSA believes that all orientation programs should include some instruction in techniques of intercultural communication. They posit that the most meaningful and memorable part of an experience abroad should be contact and communication with the host country people. Nothing more is said about intercultural communication except to contact NAFSA for materials, and help in locating expert trainers.

In orientation programs students should also review their knowledge of their own culture and its influence on them. NAFSA also recommends that students are up-to-date on current affairs and U.S. economic policy so as to be able to discuss them intelligently with interested host country people.

This publication notes NAFA's advocation for reorientation of study abroad students. They know that U.S. students do have re-entry problems, and that they can benefit from attention to them shortly before and/or soon after returning home. A primary purpose of re-entry orientation should be to carefully look at the learning from and value of the experience abroad. This summarization could include what has been learned about the people, the country, the culture and host country values. Even if only one short session is devoted to these topics it can be of great help to the students. 
Readjustment is usual1y no prob1em for students who have associated most $1 \mathrm{y}$ with fellow Americans and never truly left home in the psychological and cultural sense. However, for those who have stayed long enough and tried hard enough to become adjusted to the host culture there are many readjustment problems they may encounter. For example, problems adjusting to the busy schedules and tempo of U.S. 1ife. There can also be problems when students discover that family and friends aren't especially interested in hearing tales of the sojourner's overseas adventures.

In this publication NAFSA states that the chief remedy for these types of re-entry problems is the awareness in advance that they might occur, along with some thought on how to deal with them. Thus, at least one month before the end of the program NAFSA recommends a session or two at which the topic of readjustment is considered. For those returning to the home campus another session or two shortly after returning could also be very helpful. A follow-up session is recommended about a semester after that, to help reveal maturing ideas and separate lasting benefits from casual impressions.

Like orientation programs, nearly everyone in the study abroad field agrees with the importance of program evaluation, but few do anything substantial about it. In the Handbook for advisers and administrators are listed some evaluation steps that are simple enough that NAFSA feels 
these steps should be undertaken for every study abroad program every year.

A) Evaluation by students. Asking participants to fill out an evaluation form towards the end of the program in which they give their reaction to the program. NAFSA feels this is the minimum that should be done in evaluating a study abroad program. Along with student reaction to the experience, this will be informative as to needed improvements.

B) Evaluation by the program director. NAFSA states that program directors should be expected to submit a fairly complete report on the program's operation and his/her assessment of its success. Also included should be recommendations for desirable changes.

C) Evaluation by the committee on study abroad. The faculty committee and appropriate officials of the sponsoring campus should review the evaluations submitted by the students and director. If necessary, this committee should make recommendations for further evaluation. The committee should make recommendations for needed improvements before the program is run again.

D) Evaluation by others. For the most objective analysis of a program's operation NAFSA recommends evaluation by experienced and impartial persons not affiliated with the sponsoring institution. NAFSA offers consultation services through its field service program. They also are willing to 
suggest experienced consultants with whom direct arrangements can be made.

E) The ANTFOSA-NAFSA Evaluation Guide. The 1979 publication Study Abroad Programs: An Evaluation Guide outlines a procedure for an in-depth evaluation of study abroad programs. The procedure can be used by the institution itself, or evaluation teams can be used. This document was reviewed earlier in this chapter.

F) Long-range follow-up. NAFSA suggests that it can be quite revealing to do a follow-up study a year and/or five years later asking the same people to complete another copy of the same evaluation form they completed at the end of their study abroad experience. This could perhaps revea 1 the real values of the experience, as minor irritations and euphoric feelings of the moment have faded.

This handbook lists the most common uses for evaluations:

1) To determine the values of the experience for the participants and the changes that have taken place in their knowledge, attitudes and understanding.

2) To obtain facts to help in gaining administrative and budget support for study abroad.

3) If the evaluation is favorable, there is satisfaction in knowing that the program is working well, and it can be continued in confidence.

4) If the reaction is negative, identification of what is 
wrong is the first step in improving it.

THE CIEE GUIDE to INSTITUTIONAL SELF-STUDY and EVALUATION of EDUCATIONAL PROGRAMS ABROAD

Concern about the problems of improving overseas programs was one of the principle motivating factors in establishing the Council on Student Travel in 1947, today known as the Council on International Educational Exchange (CIEE). A committee on academic programs abroad was created in 1958 to address concerns for standards in overseas programs. This committee was responsible for the preparation of : A Guide to Institutional Self-Study and Evaluation of Educational Programs Abroad. The Guide is intended to be an aid in the process of self-study. Its function is primarily to facilitate the evaluation of overseas educational programs by the sponsoring organizations themselves. The Guide can help evaluate the results of a study abroad program by providing authoritative standards with which programs can be justified, modified or abandoned, if need be. The Guide is comprised of twenty sections which attempts to cover all of the important aspects of study abroad programs. This guide was developed by fifteen different committees involving nearly one hundred persons representing more than seventy educational institutions and organizations. Their intention was for the Guide to help systematize and facilitate the planning or evaluation process. CIEE published this guide in 1965. 
This document was essentially the only evaluation guide available until the late 1970's.

The complex network of factors that go into effective study abroad programs are far too involved to be collected into a neat set of rules. Consequently, the Guide suggests general principles which planners and evaluators should keep in mind, rather than a checklist of simple do's and don'ts.

Of these twenty sections I found six of them to be relevant to this study. After listing them, I will mention the important points from each individual section.

1) Educationa $1 \mathrm{Aims}$ and Objectives

2) Preparation and Orientation

3) The Cross-Cultural Encounter

4) Program Evaluation

5) Course Curriculum

6) Evaluation of Participant's Achievements

In the educational aims and objectives section the statement of guiding principles included several important points. When designing a study abroad program, the first and most vital task is to establish objectives. The authors also state that the educational aims of the program should be consonant with the educational aims of the sponsoring school. These aims should be supplemented by the more specific objectives which led the sponsors to place the program in another country and design it as they did. These objectives should be appropriately related to the specific educational opportunities which the host country offers. 
The program's general educational aims and specific objectives should be clearly spelled out, and adequately interpreted to applicants, participants and faculty. These aims and objectives should be reviewed and revised when necessary as part of regular evaluations of the total program. The guiding principles state that programs of study abroad may have both academic and social aims; i.e., they may be designed to promote both the student's intellectual growth and his capacity for cross-cultural understanding. They state also that language objectives should be defined to indicate the degree of mastery desired in reading, understanding and speaking.

In the preparation and orientation section, orientation is considered to be the total preparation or conditioning of an individual for an adjustment he must make abroad in order to achieve his personal aims and the objectives of the program. They go on to say "Orientation is the process of educating people to think and to respond effectively in a foreign environment; it should provide some security against 'culture shock." Orientation should include study of the participant's home country, its cultural, economic and political background, as well as that of the host country. Orientation should highlight the personal skills needed to adjust to cultural differences and should increase the individual's understanding of himself in relation to his own culture. 
Adequate information should be given about the objectives of the program. Orientation programs should begin early enough to permit reading and study before departure. Participants should be involved in discussions relating to the personal adjustments that will be required of him abroad.

Orientation leaders should be experienced in leading orientation sessions, and leaders who have been to the area should be utilized if possible. Finally the authors state that the effectiveness of the orientation program should be reviewed and measured against the performance and development of the participants while overseas.

The section of the Guide entitled The Cross-Cultural Encounter had a few points which were applicable to the part of my survey which dealt with cross-cultural involvement. It is stated that study abroad programs should include provisions not only for intelligent observation of the foreign society, but if possible, for some active participation in the life of its people. They recommend that this can be done in part through social activities, as well as study and living arrangements.

Opportunities should be given to participants to discuss differences in values and institutions with members of the host country. Participants should also be encouraged and aided in assessing their own values and their way of life in light of their overseas experience. 
Program evaluation was the fourth section of CIEE's evaluation guide that was utilized in this study. When evaluating a program the main objective is to determine whether and how well the program meets the stated objectives. The task of evaluating an overseas program may be assumed by administrators in the organization, but CIEE recommends that it is not confined soley to these people. It is recommended that the responsibility be shared with a committee of faculty, staff, or other persons not directly involved with administration. Outside consultants are also recommended to bring greater objectivity, experience and knowledge to the evaluation team. CIEE is prepared to offer references of experienced consultants. These consultants may be used to inspect the program's operations abroad, which is another desirable component of a quality evaluation. The authors of this guide posit that the evaluation process should assess the degree to which the individual was able to achieve his own goals. It should also evaluate changes in the participant's knowledge, understanding and attitudes resulting from exposure to the people and culture of the host country. Evaluation is considered to be a continuing and systematic undertaking in which the sponsoring organization appraises its activities, procedures and accomplishments in terms of the purposes which were to be served and the objectives to be achieved. It should use both objective measures and subjective 
evaluation. In evaluating programs some effort should be made to determine if some degree of cultural understanding has been achieved and to discover what changes have been made in the values and attitudes of the participants. CIEE believes that attempts should be made to secure evaluative comments from individuals in the host country who are able to observe the program. Their final point is that the findings of evaluation programs should actually be used to effect indicated changes in the program plan.

In the section on course curriculum the guiding principles state that the curriculum should include courses offered by the educational institutions of the host country except when the students' academic or linguistic backgrounds are inadequate. Also the curriculum should be related to the civilization of the host country and to the special education opportunities which exist in that country.

The final section of CIEE's publication: A Guide to Institutional Self-Study and Evaluation of Educational Programs Abroad is Evaluation of Participants' Achievements. This section begins "The participant should return from the experience with an a wareness that he has been involved in a cross-cultural exchange." If not, I would agree that either the program or the student himself have serious problems. More profoundly they go on to say that the participant's new awareness should provide a fuller understanding of cultural multiplicity, of differences and similarities between 
foreign and home culture, and of his national identity within the context of his international experience. He should be aware of changes or lack of changes in his personal behavior attitudes and ideas, and the reasons for them. And the student should be able to recognize that his identity and integrity as a person have been enhanced as a result of the experience.

EVALUATING ACADEMIC PROGRAMS ABROAD: THE CIEE PROJECT

The history of CIEE's activity in evaluating overseas education programs through their evaluation team projects is summarized in their occasional paper \#21: Evaluating Academic Programs Abroad: The CIEE Project.

In 1970 increasing concern to do more toward maintaining and distinguishing quality programs prompted CIEE to form a committee on program evaluation. Their goal was to develop a cooperative evaluation service for member institutions. The purpose of the evaluation service was that of establishing means for quality control through which member institutions would help one another improve their programs. A series of team evaluations was undertaken as a pilot project in 1972. Another series was conducted in 1975, followed by another series in 1977 .

The team was clear about certain criteria of quality they looked for in the programs they evaluated. They began with the assumption that foreign study is a good idea, and 
the teams always attempted to evaluate each program in light of the program's own stated objectives.

In program design the team looked for the following:

-- that which could not be done as well at home

-- the use of learning resources that took advantage of the local environment

-- a cross-cultural immersion in some depth

-- experiential learning in an academic context fostering intellectual rigor.

A recurring concern the teams found was the dichotomy most students and administrators see between "academic" learning and "non-academic" experience. The 1972 evaluation team observed "Much of what the student learns in overseas programs, lies in the realm often derogated by academics as the 'non-academic', but which can actually involve a high level of intellectual attainment in understanding and coping with a foreign culture." The returned students often speak with much enthusiasm about what they have learned extracurricularly, although they find it hard to be specific. The same team also observed some students had a "guilt laden attitude that 'academic' chores must be finished before the 'non-academic' explorations can begin (p.7). Sanders and Ward (1970) are quoted as defining a central purpose of study abroad programs as "the broadening of students through their total immersion in another culture" (p.78). They go on to warn against programs treating students as tourists. The authors of this CIEE document disagree with 
the assumption that to be respectable study abroad programs must replicate abroad what happens at home. They say, "... we would insist that the central purpose quoted above can be achieved only if the whole person, not merely the classroom learner in the person, is involved" ( $\mathrm{p} .7)$.

Another recurring theme was the need for more systematic methods of program evaluation. The teams observed that this area has recieved little at tention. What evidence of evaluation they found tended to unsophisticated, and tended to solicit "impressionistic responses to of ten peripheral queries". They noted an overdependence on using numbers to present convincing evidence of program quality. Counting numbers of students enrolled and comparing GPA's often replaces true assessment of program impact. This is true in part because "the most significant results of educational programs are certain qualities of mind and spirit that we do not know for sure how to contrive to inspire, let alone how to capture and translate into measurable terms" (p.8).

This evaluation project was a promising step in CIEE's long standing commitment to improving study programs abroad. However, this project was admittedly only the beginning, and the need to develop still more effective methods of evaluation was acknowledged in the final sentence of their report. 


\section{ACCREDITATION HANDBOOK}

The Northwest Association of Schools and Colleges' Accreditation Handbook was reviewed in an attempt to discover what guidelines they might use when reviewing study abroad programs.

Accreditation is a process for recognizing educational institutions that reach a level of performance, integrity, and quality which entitles them to be recognized by the educational community and the general public. Accreditation is a voluntary process extended through non-governmental agencies. The accreditation process has the potential to stimulate institutions to reach their maximum educational effectiveness.

The accreditation process begins with an institutional self-study. This is a comprehensive effort to measure progress according to their own previously stated objectives (very similar to the NAFSA self-study concept). This selfstudy report serves as the basis for an on-site team evaluation from the experts at the accrediting agency. The visiting team assesses the institution or program in light of the self-study report, and adds to it judgement based on their expert external perspective. The team then prepares its own report which is reviewed for accuracy by the institution. The self-report and the team's report are then submitted to the accreditation commission for their approval or rejection. 
Accrediting agencies do not assess and evaluate study abroad programs which are not related to the curricula of specific colleges or universities undergoing the accreditation process. However, when study abroad programs are a part of a school's curricula that is seeking accreditation, the study abroad programs are evaluated against a set of guidelines set forth in the Commission on Colleges' Accreditation Handbook. Below is a brief review of these fifteen guidelines:

The Commission on Colleges urges that study abroad programs should:

1) be clearly related to the objectives of the sponsoring institution

2) have a well defined rationale stating the nature and purposes of the program

3) provide educational experiences related to the institution's curriculum

4) be available to students who are carefully selected

5) have a carefully articulated financial aid policy

6) have clearly defined language proficiency requirements, and well defined methods of testing proficiency

7) provide extensive information to intended participants

8) provide extensive orientation for participants prior to departure and on arrival abroad

9) have a carefully selected professionally competent resident director

10) provide counseling and supervisory services abroad

11) guarantee adequate basic reference materials abroad

12) clearly define criteria for judging performance and assigning credit, and have a common basis for 
determining grade equivalents

13) stipulate that students must plan and obtain approval in advance for foreign study undertaken

14) include provisions for follow-up studies on the individual and institutional benefits derived from such programs

15) assure fair reimbursement to participants if the program is not delivered as promised for reasons within the sponsor's control

\section{SUMMARY OF PROFESSIONAL LITERATURE}

After reviewing the previous literature that has been published by professionals and national organizations that concern themselves with study abroad programming several recurring themes became evident. These themes ran across all or most documents and therefore are assumed to hold some degree of importance to these professional organizations.

These themes were used extensively in creating the questionnaire used for this project. These themes will be briefly reviewed below:

1) Program objectives should be clearly defined.

2) Objectives should be made known to the students.

3) The curriculum should be related to the program's goals and objectives.

4) Study abroad programs should be consistent with the basic purposes of the home institution.

5) Study abroad programs should be of at least equal academic rigor to the home institution.

6) Study abroad programs should offer unique study 
opportunities not available at the home campus.

7) Courses should be related to some degree to host country culture, and should be modified to make use of the host country environment.

8) Academic learning should be integrated with crosscultural learning.

9) There should be a meaningful degree of cross-cultural immersion which allows active participation in the daily life and activities of the host culture.

10) Social informal programs should be a part of study abroad programs.

11) Students should become aware of their own culture and its affect on them.

12) Students should learn about host country culture.

13) A cultural orientation should be provided.

14) A re-entry program should be offered to help students creatively use the foreign experience and integrate their experience and themselves back into their home environment. 15) Provisions should be made for program evaluation. 16) Academic and cross-cultural program aspects should be evaluated against stated goals and objectives.

17) Evaluations should be conducted by more than one person, such as a 11 or a combination of students, program directors, faculty and outside consultants.

18) Evaluation findings should be used to improve future programs. 


\section{REVIEW OF INTERCULTURAL COMMUNICATION CONCEPTS RELEVANT TO STUDY ABROAD}

As mentioned in chapter 1 , the study of intercultural communication is a relatively new discipline. However, the theoretical contributions that have emerged have the potential to improve the study abroad experiences of student so journers through improved communication competence. Because these communication strategies do exist, they can be incorporated into orientation programs and/or into regular course curriculum offered on study programs abroad.

Pearce and Cronen (1980) define communication competence as "the person's ability to move within and among the various systems s/he is cocreating or comanaing" (p.187). This ability to manage a variety of rule systems is important for effectiveness as a communicator, especially when communicating across cultures.

In a report of their survey of teacher education programs, Klassen, Imig and Iff (1972) stated that the millions of dollars that have been spent to prepare and disseminate curriculum materials that would incorporate international or intercultural concepts have produced an important body of materials - which "are too often neglected or ignored in professional preparation programs" (p.38).

It is today becoming recognized that study abroad 
program administrators have an ethical responsibility to provide at least minimal training in the concepts and skills of intercultural communication (Barnlund, 1982).

For this study selected intercultural communication literature was reviewed to locate those concepts which experts agree have direct applicability to training programs which are designed to prepare student sojourners for study abroad experiences.

What follows is a list of the concepts which were selected and a rationale for their inclusion in this study. Each concept will be reviewed briefly. It is not my intention here to review all literature published on these concepts or to pursue each in its fullest complexity.

\section{CULTURE SHOCK}

"Culture shock" is the term used to describe the more pronounced reactions to the psychological disorientation most people experience when they move for an extended period of time into a culture markedly different than their own (Koh 1s, 1979). When we encounter a different culture, we are usually deprived of the supports and identity reinforcements that are available in our own culture. Differences in language alone can be enough to cause anxiety and disorientation. The impact of culture shock on an individual can range from mild discomfort to radical emotional dislocation and an inability to function in that 
environment (Hoopes, 1981).

According to David $S$. Hoopes there are four basic responses to culture shock. These are often identified in cross-cultural training programs. They are:

FIGHT- This is the basic "we/they" response. Ethnocentrism becomes common, and the other culture is seen in a negative light.

FLIGHT- This response involves a retreat from interaction with the other culture along with increased immersion in one's own culture.

GOING NATIVE- In this response individual's acculturate rapidly to their new environment. They superficially mimic the host culture and also attempt to drop their cultural identity. This is viewed as another form of flight because it is a form of escape from the complexities, difficulties and rewards of the intercultural experience.

ADAPTATION- This response to culture shock consists of finding ways to comprehend and adjust to the other culture, while still affirming one's own culture.

For some people culture shock is brief and hardly noticeable. For others it may last a month, a year, or until they return to their own familiar home culture.

\section{STEREOTYPES and GENERALIZATIONS}

People cannot deal with each and every piece of information that competes for their attention (Brislin, 
1981). The aspects of culture are so numerous that various discrete stimuli must be categorized for more efficient organization. People then behave according to the category they have organized, not according to the discrete stimuli (Triandis, 1977). Often these categories are stereotypes which do not allow for variations within a category.

Stereotypes refer to any categorization of individual elements concerned with people which mask differences among these elements. Stereotypes are a type of generalization which involve the name(s) of some group of people and statements about that group (Brislin, 1981).

Student sojourners sometimes generalize from very limited experiences in another culture. These preconceived ideas can have negative effects when communicating interculturally. With proper training students can be made aware of the tendency to stereotype. With this awareness they can seek more information before forming a category, and can be made aware that stereotypes should always be open to modification as more information becomes available (W. Scott, 1965). All people stereotype, but some are more aware than others that any stereotype should be open to modification (Harvey, Hunt \& Schroder,1961).

The most effective sojourners have open minds which al low categories to be modified with experience (Brislin, $1981)$. 


\section{ETHNOCENTR ISM}

Ethnocentrism is defined by Webster's dictonary as "regarding one's own race or cultural group as superior to others." Ethnocentric people tend to view other people unconsciously using their own reference group and their own way of doing things as the standard for judging others. This narrow way of viewing the world stems from a belief that "our culture is central to reality." This denies the fact that there are other frames of reference for viewing the world that may be just as valid as our own. Differences are perceived in a negative light and similarities are seen as positive.

Samovar and Porter (1976) outline well the dangers of ethnocentrism for sojourners, "When we allow ethnocentrism to interfere with our social perception, the effectiveness of intercultural communication is reduced because we are unable to view aspects of another culture that differ from our own in an objective manner." They go on to say..."at the extreme, ethnocentrism robs us of the willingness and desire to communicate interculturally" (p.11).

\section{TOLERANCE of AMBIGUITY}

Brislin (1981) defines tolerance of ambiguity as "an ability to think about problems and issues even though al 1 facts and probable effects of decisions are not known" (p.55). All cross-cultural encounters are ambiguous. It is 
important to remind student sojourners of this fact. To be successful communicating in another culture one must be flexible enough to tolerate ambiguity. Tolerance for ambiguity has been found to be associated with crosscultural success. If students can act appropriately in ambiguous situations without becoming traumatized by the stress involved, they have a higher degree of potential to be successful abroad.

\section{CULTURE-BASED BEHAVIORAL NORMS, VALUES,} ASSUMPTIONS and BELIEFS

Unlike basic communication theory that is based on finding similarities between the communicators, intercultural communication is based on discovering and appreciating cultural differences (M.Bennett, 1979). Thus in intercultura 1 communications training for study abroad students it is important to help them understand both their own culture-based behavioral norms, values, assumptions and beliefs, and those of the host country they will be visiting .

It is a culture's value system which sets the norms for behavior in that society. Acceptable conventions for norms of behavior are learned. The same norm may also be expressed differently across cultures.

Edward C. Stewart (1972) notes an important difference between values and assumptions. He says values are a statement of what should be, they have a quality of 
"oughtness" to them. Assumptions on the other hand, are basic beliefs or perceptions of reality which lie behind values and affect the way people behave. Values are culturally derived notions of right and wrong, good and bad, etc. Our own values and assumptions are not absolute truths, because they are subject to cultural variation.

Students should be given opportunities to discuss differences in behavioral norms, values, assumptions and beliefs with members of their own culture group and if possible with members of the host culture.

\section{CULTURAL SELF-AWARENESS}

One of the main sources of intercultura 1 misunderstanding happens when we are not aware of the "out of awareness" influences our culture has upon us (Hoopes,1981). Our culture helps to deeply root and condition our perceptions of reality. Thus it can be helpful for students going abroad to review their knowledge of their own culture and its influence on their own thinking. Cultural self-awareness training is today recieving strong support in the literature on intercultural education and training ( $J$. Bennett, 1984). Individuals have a higher probability of functioning sucessfully overseas if they develop an awareness of their own cultural perceptions. Janet Bennett has outlined eight primary learning outcomes which emerge from the literature on cultural self- 
awareness. These are the types of outcomes study abroad programs may want to encourage. By increasing cultural self-awareness, educators anticipate that students will be able to:

1) Achieve greater self-awareness

2) Increase their ability to empathize across cultures

3) Increase their motivation to learn while abroad

4) Develop cultural relativity

5) Withstand culture shock more effectively

6) Increase recognition of their preferred values

7) Distinguish cultural from idiosyncratic personality traits

8) Increase effectiveness in intercultural interactions

\section{AWARENESS OF HOST COUNTRY CULTURE}

Orientation programs and course curriculum can be designed to he1p students become aware of the culture of the host country. This can be done in conjunction with cultural self-awareness training. Investigating the culture of the host country is sometimes refered to as the "culture specific" aspects of a training program (Brislin \& Pederson, 1976). The orientation program should prepare the participants to analyze their own culture and to approach the foreign culture both critically and with understanding"? 


\section{CULTURAL RELATIVITY}

Wasilewski and Seelye (1981) state "To understand cultural relativity is to recognize that different cultures provide different behavioral options for satisfying the universal physical and psychological needs of Homo sapiens." Cultures should not be judged or evaluated from a single moral or ethical perspective. Evaluations are relative to the background from which they arise (Hoopes \& Pusch 1981).

\section{MULTICULTURALITY}

Multicultural persons are considered to be people whose actions and thoughts reflect more than one culture (Adler, 1979). It has been argued that all people are multicultural. Virtually no one is purely monocultural or bicultural (Hoopes \& Pusch, 1981). As student sojourners expand their cultural identities through intense crosscultural experience they may begin to move further away from being monocultural.

In developing the concept of "multicultural man," Adler (1979) suggested that successful sojourners have a number of qualities which distinguish them from people tied to the culture into which they were born. Multicultural people: (a) are adaptive when faced with difficulties and can interact in many situations regardless of the culture in which they find themselves;

(b) are continually undergoing personal transitions since they are always finding new 
challenges in the different situations; and (c) can look at their own culture from the perspective of an outsider.

There is, according to Adler, a potentially bad side to multiculturality. It is possible to feel a sense of homelessness from viewing one's own culture from the perception of an outsider. A diffuseness of identity could occur also. It is perhaps only ethical to warn students of the possibility of this occurrence. However, the relatively short duration of most study abroad programs will probably on 1y begin to make students truly multicultural.

\section{PERCEPTION}

Perception is another area which was used as a reaction item in the survey used in this study. The concept of perceptual difference across cultures is a difficult idea to internalize. Perceptual difference basically means that the screens we use to filter the mass quantities of sensory stimuli we are exposed to every day is also culturally determined. Our own perceptions can be so deeply ingrained that we never stop to question them (Singer, 1976).

The stimuli we may pay attention to may be totally screened out by people from other cultures. The data that we do perceive we tend to classify or categorize as a way to sort out and understand it. How we make these distinctions is based largely on our culture (Hoopes, 1981).

A main implication this has for communicating 
interculturally is that we can get confused when our experiences abroad don't fit into our normal categories. This can produce anxiety and ambiguity. Thus it can be helpful to learn or understand other sets of categories by which to judge experiences.

\section{LISTENING and FEEDBACK}

Listening is a skill, and our failure to listen carefully contributes significantly to human mis communication (Hoopes, 1981). Because of differing styles of communication across cultures it can be difficult to know what to listen for. One must try to 1 isten to verbal and non-verbal messages without filtering them through our own system of values and expectations.

Seeking feedback can be helpful when communicating across cultures, but, as Hoopes points out, asking for feedback can be emotionally risky. It may seem easier and safer to assume you are being understood.

By alerting students to their own listening and feedback skills they will be better able to note differences in the host culture.

\section{DIFFERENCES IN COMMUNICATION STYLE}

Over a long period of time each culture has developed its own style of communication. These differences feel "natural" but can be perceived as bad by others because by 
nature we accept our own way of communicating as natural (Hoopes, 1981). Different styles of communication can be very confusing and frustrating. Most people have not had any training in intercultural communication skills to help them cope with differences in communication styles. As mentioned previously, intercultural communication focuses on differences and how to cope with them and even appreciate them (M.Bennett, 1979). David S. Hoopes posits that, "Differences...constitute both the essence of cross-cultural learning and the medium of intercultural communication" (p.33).

Students preparing to go abroad can be made more aware of specific cultural differences in communication styles of the host country, as well as general intercultural communication skills.

\section{CULTURAL ADAPTATION}

In cultural adaptation the individual adjusts to the problems and challenges of living in another culture so as to feel comfortable and to function effectively within the culture. Adaptation differs from true assimilation into the culture in that the person "plays along" with the new cultural behaviors, but doesn't let the new culture encroach on his own cultural identity (Kohls, 1979). 
COPING STRATEGIES

In cross-cultural adjustment.difficulties which demand coping responses are normal and expected. The basic difficulty is that sojourners are faced with problems for which they have no familiar response (Brislin, 1981).

Most people use different coping strategies to meet different demands at different times. These strategies are of ten used by sojourners to respond to culture shock. Seelye and Wasilewski (1979) identified five types of coping strategies. They are:

Nonacceptance- Sojourners behave as they would in their own country. They refuse to spend the time and effort learning host country norms.

Substitution- Sojourners learn the response judged most appropriate by the hosts and behave accordingly.

Addition- Sojourners make a judgement regarding appropriateness of behavior, and then behave either as they would at home or according to host country norms.

Synthesis- Sojourners combine and integrate elements from different response patterns.

Resynthesis- Refers to an original integration of ideas not found in either cu1ture.

\section{TIME ORIENTATIONS}

Different cultures tend to have different orientations toward time. Western cultures tend to conceptualize time in 
lineal-spatial terms, meaning that we are aware of a past, a present, and a future. Time is something we can manipulate, something we can save, waste, make up, or spend. To an American who treats time as a commodity it can be confusing to communicate with someone with a much different temporal orientation such as a a Japanese Zen who treats time like "a limitless pool in which events occur, cause ripples, and then subside" (Samovar \& Porter, 1976, p.21).

Cultural differences in temporal orientations can effect the norms concerning communication sequences. Culture determines when a response is too fast or slow, along with how fast a person talks. This can cause errors in the messages we recieve when communicating intercultura11y.

\section{ETHICS OF CROSS-CULTURAL ENCOUNTERS}

Intercultural ethics may be thought of as principles of conduct that govern the behavior of individuals and groups when they are in a culture different from their own (Paige \& Martin, 1983).

Howel1 (1981) states that ethics are culturally contextualized and thus are relative. Orientation programs should not simply ignore ethical differences when preparing students to study abroad. Every culture has articulated a set of ethical precepts. However there has been no universally accepted formulation of what is ethically 
responsible in intercultural encounters (Barnlund, 1982).

Howell proposes an operational ethics of intercultural communication which consists of three major points:

1) Learners should be provided with sufficient information about the host culture so that they can make an informed decision about entering into it or not.

2) Training should promote the acquisition of enough personal flexibility regarding one's own and the target culture's ethics so as to enable the sojourner to be empathic with the new culture and to deal effectively with cultural differences.

3) Educators and learners should adhere to the Principle of Social Unity, i.e., "no action is ethical if it harms persons affected, and the action that benefits affected persons accumulates ethical quality" (Howell, 1981, p.8).

\section{EMPATHY}

In a speech to the American Psychological Association in 1979 , Kenneth B. C1ark defined empathy as "the capacity of an individual to feel the needs, the aspirations, the frustrations, the joy, the sorrows, the anxieties, the hurt, indeed the hunger of others as if they were his own". Empathy has also been defined as "the imaginative intellectual and emotional participation in another person's experience" (M. Bennett, 1979, p.418). When one can imagine how others feel, acknowledging that that might be different 
than how he would feel in that same situation, and can respect and acknowledge that difference he is communicating with intuitive empathy. There is also cognitive empathy which is trying to construct the world view of the other by seeking information through reading or just plain asking questions (M. Bennett, 1979).

In intercultural communication situations empathetic people can better understand how they are being perceived by others. However empathy's main value lies in the ability to shift our perspective away from ourselves so as to acknowledge the other person's experience.

\section{SUMMARY}

The recurring themes that were extracted from the professional organization's publications reviewed in the first part of this chapter, coupled with the intercultural communication concepts reviewed in the second part of this chapter comprise to a large degree the theoretical framework used in creating the survey instrument. These concepts will be referred to in the following three chapters.

The survey will attempt to determine the extent to which study abroad programs are using these relevant intercultural communication concepts and the guiding principles and standards specified by respected professionals and organizations in the study abroad field. Program directors will also be asked how important they feel 
these concepts and recurring themes are. This will help determine how well perceived items of importance are matched between the organizations who establish them and the program directors who may or may not administer them. 
CHAPTER III

\section{METHODS \\ CREATION OF THE SURVEY INSTRUMENT}

As stated in chapter one, this is a descriptive research project. The survey instrument used in this project was created with the intent of assessing some of the conditions of study abroad programming by measuring program directors perceptions of these conditions within their own programs abroad (See Appendix A).

Descriptive data-collection techniques fall into three general categories: surveys, interviews, and observations (Tucker, Weaver, and Berryman-Fink, 1981). A survey format utilizing a written questionnaire was chosen as the most efficient means of obtaining the necessary information. The survey format was al so appropriate because as of yet, this type of information does not exist in public records or documents. Study abroad program administrators are the sole keepers of this information.

The type of questions used in this questionnaire were all closed or structured except the final one which asked for optional comments on the questionnaire or the topics themselves.

Four of the questions required simple yes-no answers. 
Eight of the questions used in the questionnaire were multiple choice check list type in which respondents checked one or more short phrases which apply. The remaining fiftysix questionnaire items asked the participants to rate their responses to various questions or statements on a numerical Likert-type scale. The numbers progressed from a minimum of one to a maximum of seven. The scales were anchored with one being "not at all important" or "not at all", and seven being "very important" or "to a great extent". Avoiding open questions eliminated the need to subjectively interpret the data. All statistical analysis could thus be done numerically. 
ORIGIN OF THE SURVEY QUESTIONS

The questions used in this questionnaire came primarily from the literature review undertaken for this study. In most cases, the questions were derived from theoretical concepts stated in the literature. To develop many of the questionnaire items the open ended evaluative questions from the ANTFOSA Guide and the CIEE Guide were rewritten, turning them into closed questions.

I will briefly discuss the origin of questions below.

Section I. GOALS and OBJECTIVES

The first question asked how the program's goals and objectives are made known to students. This addresses an is sue raised by The Council on International Educationa 1 Exchange in their evaluation project. They feel that aims and objectives of study abroad programs should be made explicit to applicants, then programs should focus on those areas rather than attempting to offer all things to al 1 people. The first two answers program directors could check if they applied were: They (goals and objectives) are stated in the printed materials, and, They are discussed during orientation. Both of these choices came directly from the NAFSA ANTFOSA Evaluation Guide. These are considered by NAFSA to be two good ways to make program 
goals and objectives known to students. The third possible answer was: They are discussed during personal interviews. In their Study Abroad $\mathrm{H}$ andbook for Advisers and Administrators NAFSA states that this area should be discussed with a qualified study abroad adviser. The final answer that could be checked was: They are assumed to be understood by the students. This is one of the negative responses given in the ANTFOSA Guide.

Question number two asked: How important do you feel it is for your institution to clearly state the goals and objectives of the study abroad program? This stems from NAFSA's feeling that this information should be stated in the printed materials, and from the CIEE Guide which asks: "Are the program's general educational aims and specific objectives clearly spelled out?"

The third question comes from a NAFSA principle concerning the idea that expected outcomes of participation in study abroad programs should be well defined and articulated. Greater maturity and seriousness are frequently reported outcomes of study abroad according to NAFSA •

Question number four asks program directors how important they feel it is to insure that courses offered by the U.S. faculty are modified to make use of the host culture enviroment. Both NAFSA and CIEE feel the curriculum should make use of the resources provided by the host 
culture. The NAFSA Handbook states ..."there are very few subject fields so uniquely American that there can be no benefit from studying their international and comparative aspects in another country" (p.31). This issue will be pursued further in the next section on cross-cultural involvement.

The fifth question asks how important foreign language proficiency is in achieving the goals and objectives of the program. The NAFSA Study Abroad Handbook posits "Study abroad is no longer the prerogative of the foreign language major" (p.31). The ANTFOSA evaluation guide states that language requirements should be consistent with the program's objectives. Also adequate language courses and facilities should be available, and the library holdings should reflect the level of language proficiency required.

Question six asks: How important are the following goals and objectives for your program? There are then fifteen goals and objectives A through 0 listed to respond to individually.

Parts $A$ and $B$ come straight from the objectives section of the ANTFOSA evaluation guide that says that one program objective should be: "to combine academic learning with cross-cultural learning experience" (p.2). They go on to say that undergraduate education should be enriched"by offering study opportunities which are not available in the United States" (p.2). 
Parts C through H come directly from an unpublished Doctoral thesis done by Janet Bennett in 1984 at the University of Minnesota. The study was entitled: Intercultural Communication Training In Cultural SelfAwareness For Study Abroad. The study dealt with some of her work with the Northwest Interinstitutional Council on Study Abroad (NICSA). This organization is a consortium of 14 public colleges in the northwest. For the research project Bennett developed a questionnaire to determine the goals of the NICSA organization and the participants. Parts C through $G$ were based on interviews with the NICSA staff and the goals most frequently cited in study abroad literature (Abrams, 1960, p. 4-5; Carrol1, 1974, p.30; Coelho, 1962 p.56; Gullahorn and Gullahorn, 1958 p.369; 1966, p.44; Mishler, 1965, p.557-8). Part H is the primary stated goal of the NICSA organization. These six goals are:

C) To stimulate academic achievement in an environment relevant to the subject

D) To provide an opportunity for intensive foreign language study

E) To increase awareness of the students' role in his or her own culture

F) To achieve understanding of another culture

G) To encourage personal development

H) To broaden a liberal arts education

Question 6 parts I and $J$ of the survey instrument were 
derived from an evaluation questionnaire used in Janet Bennett's thesis study. This evaluation questionnaire asked NICSA student participants to rate the degree of accomplishment of the three main goals of the NICSA training program. The goals were reworded slightly to better suit my study. The two of the three main goals of this NICSA program utilized in my survey were:

I) To increase cross-cultural sensitivity (to increase program participants' ability to recognize and respect differing cultural characteristics)

J) To develop intercultural communication skills (to increase program participants' ability to communicate effectively in other cultures)

The final part of section one question six, items $K$ through 0, came from a report prepared in 1955 by the Committee on Education Interchange Policy of the Institute of International Education (IIE). This report summarizes the goals that were generally expressed by institutions who sponsored study programs abroad. These five goals in order of frequency are:

K) To promote international understanding and good will among the peoples of the world as a contribution to peace.

L) To develop friends and supporters for the United States by giving persons from other countries a better understanding of the life and culture of the United States. 
M) To contribute to the economic, social or political development of other countries.

N) To aid in the educational or professional development of outstanding individuals.

0) To advance knowledge throughout the world for the general welfare of mankind (Gullahorn and Gullahorn, 1958. p.369).

\section{Section II. CROSS-CULTURAL INVOLVEMENT}

This section of the questionnaire is made up of four questions dealing with cross-cultural involvement.

Questions number one and three come directly from the ANTFOSA evaluation guide's section on cross-cultural involvement. NAFSA states that for quality programs "The curriculum includes courses which focus specifically upon the host culture and which require involvement through research assignments and field work" (p.4). The second question of this section is similar, except it deals with informal out-of-class experiences which may have educational value. The NAFSA Standards and Responsibilities book sums up NAFSA's feelings well on this topic: ..."informal, out-of-class experiences, if well planned and executed, can and should be encouraged as an integral part of an international education program" (p.13). This "incidental learning" is often reported by students to have been one of the most valuable parts of their experience 
abroad.

Question four comes from NAFSA's advocation that the curriculum of a study abroad program should benefit from the "extensive and effective use of the unique physical, human and cultural resources of the host environment. Program resources (should) provide en richment unattainable in the United States" (ANTFOSA, 1979, p.3).

\section{Section III. ORIENTATION}

The questions in this section came to a large degree from the positive responses given as hypothetical answers in the ANTFOSA evaluation guide. According to this guide there should be an orientation program conducted that goes beyond the logistical instructions such as payments, passports, visas and transportation arrangements before departing on a study abroad program. As mentioned in chapter II, NAFSA feels that ideally orientation should begin soon after particpants are selected and should continue throughout the students' sojourn. The Council on Student Travel mentioned in A Guide that orientation should begin early enough to permit reading and study before departure. Questions four and five deal with the different types of orientation methods and orientation resources that were reviewed in chapter two.

Question six of this section asks about what types of teaching methods are used in orientations. Beyond the more 
common methods such as lectures, discussions and readings several less common teaching methods were asked about.

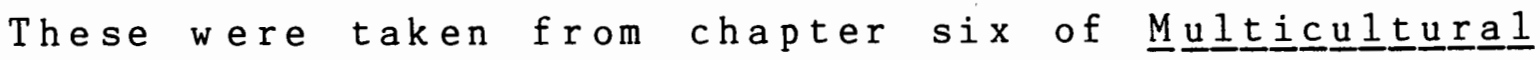
Education: A Cross Cultural Approach. This chapter was written by David S. Hoopes and Margaret D. Pusch in 1981. These teaching methods include simulations, role plays, case studies and critical incidents.

Question number seven stems from the section in A Guide on program evaluation. A guiding principle in this section is that any evaluation of an overseas program should provide information concerning the orientation program. They also state that when evaluating a study abroad program, a question that should be asked is: Is the effectiveness of the orientation program reviewed, measured against the performance and development of the participants while overseas? Another evaluative question CIEE would ask is: How adequately does the orientation program prepare participants for the personal, social or academic adjustments which the program requires?

Question number eight of this section lists eighteen different reaction items. Each of these items has been advocated by professionals in the study abroad field and/or the intercultural communication discipline to be important topics to include in orientation training programs and/or course curriculum of study abroad programs.

These items were each reviewed individually in chapter 
two in the section on intercultural communication concepts relevant to study abroad.

The next two questions ask if a re-entry orientation program is offered before or soon after students return to the United States, and if so what types of re-entry problems are covered in the program. The ANTFOSA Evaluation Guide considers it to be a plus if "a pre-return orientation program is offered to alert students to problems of re-entry into the home environment and ways to use the foreign experience creatively" (p.4). Warning students that they may have re-entry problems and giving some advance thought to these problems is considered by NAFSA to be the best way to remedy "re-entry shock".

\section{Section IV. PROGRAM EVALUATION}

There are five questions which deal with the subject of program evaluation. The questions come primarily from the Council on Student Travel's: A Guide To Institutiona $\underline{\text { I }}$ Self-Study and Evaluation of Educational Programs Abroad and NAFSA's ANTFOSA evaluation guide. The questions simply ask what provisions are made for overall program evaluation, which aspects of study abroad programs evaluations focus on, and when evaluations are done. The fourth question goes on to ask respondents how important they feel it is to use the findings of the evaluation methods to effect indicated changes in the program plan, and if findings of the 
evaluation are actually used to make changes in the program. The fifth question comes out of the introduction to the Institute of International Education's book: U.S. CollegeSponsored Programs Abroad: Academic Year. IIE asks program sponsors if evaluations of their programs are made available to interested program participants as a way to help them decide if they would like to apply to the program. Their surveys found that most programs are regularly evaluated, but it did not follow that these evaluations were available to potential participants (1984). This same question was included in the questionnaire for this study to see if the same results are obtained. This book will be discussed further in the next section as it was used extensively in the respondent selection process.

Question number six of the final section asks study abroad program directors if their institution formally endorses the NAFSA Principles for International Educational Exchange. These Principles were discussed in chapter II. All NAFSA members have been asked by NAFSA to endorse these Principles.

Question number seven asks the respondents if they would be willing to complete a questionnaire similar to this one in a week or two. This was included as a way of recruiting volunteers to participate in a reliability study to test the reliability of this survey instrument. The reliability study will be discussed in chapter five. 


\section{THE RESPONDENT SELECTION PROCESS}

The Institute of International Education (IIE) 1 ists the five general ways a student can study abroad in their 1982 publication Basic Facts on Foreign Study. They are:

1) Direct enrollment in a foreign university as a degree candidate or as an occasional or special student.

2) Enrollment in a special program for foreign students at a host university.

3) Enrollment in a program sponsored by a U.S. college or university. (This may be done in cooperation with a foreign university.)

4) Enrollment in a program sponsored by an organization other than a college or university.

5) Enrollment in an international or U.S. college abroad.

In this study I surveyed exclusively programs of the third type, programs sponsored U.S. colleges and universities. All programs surveyed were sponsored by recognized degree-granting U.S. colleges and universities which sponsor programs during the academic year and which offer regular U.S. credit.

The Institute of International Education (IIE) annually updates and publishes a book entitled U.S. College- 
Sponsored Programs Abroad: Academic Year. The book lists all study abroad programs of this type. The book is intended as a guide to help the student make a preliminary selection of possible study programs abroad. The 1984 edition lists 928 U.S. college-sponsored programs sponsored by 548 different institutions. Some of the programs are cosponsored and some are sponsored by consortia of U.S. institutions.

It was decided to do a random sample of 200 of these programs for this research project. It was decided also not to allow repeats of the same sponsoring institution having two or more of its programs chosen. This was decided under the assumption that different programs offered by the same school may be run in a similar fashion and/or under the same director.

To choose the random sample of schools, I turned to Index 1 in the back of this book which lists all the sponsoring institutions in alphabetical order along with the numbers 1 through 928 of the program(s) they sponsor. Each institution was numbered 1 through 548. A set of script tickets numbered 1 through 548 were placed into a brown paper bag. At random 200 of these tickets weredrawn out of the bag marking the chosen institutions in the book's index. If a chosen institution sponsored two programs a flip of a coin was used to determine which program would be surveyed. If a chosen institution sponsored more than two 
programs, a roll of the dice determined which one would be surveyed. The chosen program number would then be noted in the main text. Because of cosponsorships and consortia there were several programs listed under more than one institution. This caused some repeats. Repeats were discarded and new numbers were drawn out of the brown paper bag until there were 200 different institutions with no repeated programs. 


\section{THE SURVEY PROCEDURE}

The questionnaire went through several revisions before my advisory committee and $I$ were satisfied with it. The questionnaire was then distributed as a pilot study to thirteen professionals involved with study abroad programming. The cover letter explained that $I$ was running a pilot study to test the instrument, and would appreciate any comments or criticisms on the questionnaire's design, content, or other problems they might foresee. (See Appendix B).

Responses were received from nine of the thirteen selected for the pilot study. The feedback received was helpful, and lead to some content and format changes in the final survey questionnaire.

Each program entry 1 isted in the Institute of International Education's book, U.S. College-Sponsored

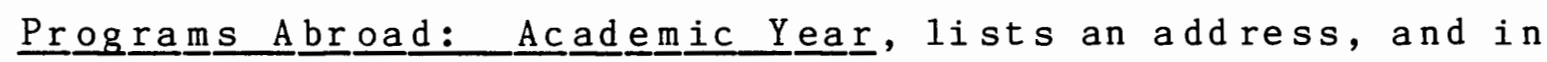
most cases a contact person to write to for more information on their program. The contact person of the 200 chosen programs was sent a copy of the final questionnaire. If no contact person was listed the envelope was addressed to the program director.

The cover letter (Appendix C) was careful1y constructed because participation in surveys of this type 
have to be elicited by virtue of the apparent usefulness of the procedure (Smith \& Kenda11, 1963). This was done by attempting to induce positive perceptions of the importance of the research and the value of their contribution. A copy of the research results was offered as a small incentive, and a postage-paid envelope was included.

It was hoped that this survey would have value for those who chose to complete it because it provided a 1 ist of ideas that program sponsors perhaps should be thinking about if they have not previously considered them.

A deadiine of close to three weeks was given for completion of the questionnaire. After three weeks a follow-up postcard was sent encouraging those who had not responded to do so, assuring them it was not too late.

To test the reliability of the survey instrument the same questionnaire was given again to a subset of the original sample. This was done approximately three weeks after the origina 1 questionnaire was administered. To recruitvolunteers for this reliability study, the last question of the survey asked respondents if they would be willing to complete a questionnaire similar to the original in a week or two. The subjects were not told why they were being asked to do this so as not to contaminate the retest. The second survey was exactly like the first al though the question stated it would be a "similar" questionnaire.

The results of the reliability study will be reported 
in chapter five, where they will accompany a discussion of their effects on limiting the study 
CHAPTER IV

\section{PRESENTATION OF DATA}

Of the 200 questionnaires that were sent to a random sample of study abroad program directors nationwide for this research survey, 115 usable questionnaires were returned. This is a response rate of $57.5 \%$. There exists no absolute cut off point for determining an adequate response rate (Tucker, Weaver,Berryman-Fink, 1981, p.96). However, some researchers (Lin, 1976), have supported general guidelines for determining the adequacy of response rates. $50 \%$ or higher is considered adequate, and $60 \%$ or higher is considered good, and $75 \%$ or higher is very good (p.241). For the purposes of this study this researcher and his advisory committe were pleased to have received 115 usable responses.

Because this is a descriptive research project, descriptive statistics will be used in presenting the data, as apposed to inferential statistics. Tucker, Weaver and Berryman-Fink write, "as the words connote, descriptive statistics provide summary information about a class of human beings or entities- and it stops at that." They go on to say, "Descriptive statistics make no statement as to the value of the information. Nor do they attempt to relate the 
information to anything else" (181).

In the remainder of this chapter the data collected will be presented with measures of central tendency, and variance statistics such as the range of scores and the standard deviation.

\section{GOALS AND OBJECTIVES}

The first of the four sections in the questionnaire asked program directors about the goals and objectives of their study abroad programs.

Question one asked: "How are your program's objectives made known to students ?" Respondents were asked to check all of the five given choices that apply. Table IV A below shows question one's reaction items, total number of responses for each item, and the percent of possible responses out of 115 .

\section{TABLE IV A}

NUMBER OF RESPONSES AND PERCENT OF

TOTAL RESPONSES FOR QUESTION ONE

ITEM N $\quad \mathrm{N}$

$\begin{array}{lrr}\text { Stated in printed materials } & 105 & 91 \% \\ \text { Discussed during orientation } & 91 & 79 \% \\ \text { Discussed during interviews } & 83 & 72 \% \\ \text { Assumed to be Understood } & 7 & 6 \% \\ \text { Other } & 14 & 12 \%\end{array}$

Fourteen respondents checked "Other", and some listed 
what other way they had of making their program's objectives known to students. Three of the more interesting ways included "school newspaper articles", "students design own goals with supervision", and "word of mouth from previous participants".

The remaining four questions of this section asked for responses on 1-7 Likert-type scales, number "one" being not at all important, and "seven" being very important.

The questions were:

2) "How important do you feel it is for your institution to clearly state the goals and objectives of the study abroad program?", "To what extent is this policy (if any) being implemented?" Number "one" being not at all, and "seven" being to a great extent.

3) "How important do you feel it is to define and articulate the expected outcomes of participating in your program for prospective students?", "To what extent is this being accomplished?"

4) "How important do you feel it is to insure that courses offered by U.S. faculty are modified to make use of the host culture environment?", "To what extent is this being accomplished?"

5) "How important is foreign language proficiency in achieving your programs objectives?", "To what extent is foreign language learning an integral part of the program?" Table IV B below shows the mean ratings for questions 
2-5, the number of respondents for each, the standard deviation, and the range of scores.

\section{TABLE IV B}

MEAN RATINGS OF GOALS AND OBJECTIVES

FOR QUESTIONS 2-5

$\begin{array}{ccrrrc}\text { QUESTION } & \text { PART } & \text { N } & \text { MEAN } & \text { SD } & \text { RANGE } \\ & & & & & \\ 2 & \text { IMPORTANCE } & 114 & 6.50 & 0.84 & 3-7 \\ 2 & \text { EXTENT } & 113 & 5.91 & 1.09 & 3-7 \\ 3 & \text { IMPORTANCE } & 111 & 6.05 & 1.34 & 1-7 \\ 3 & \text { EXTENT } & 108 & 5.38 & 1.28 & 1-7 \\ 4 & \text { IMPORTANCE } & 89 & 6.50 & 1.03 & 1-7 \\ 4 & \text { EXTENT } & 84 & 6.05 & 1.22 & 2-7 \\ 5 & \text { IMPORTANCE } & 95 & 5.40 & 1.97 & 1-7 \\ 5 & \text { EXTENT } & 108 & 5.57 & 1.93 & 1-7\end{array}$

Question six of the Goals and 0 bjectives section asked: "How important are the following goals and objectives for your program?" There are then listed fifteen different goals and objectives A through 0 , to respond to individually. Listed below is goals and objectives A through J.
A) To integrate cross-cultural learning with academic learning
B) To create unique study opportunities which are not available in the United States
C) To stimulate academic achievement in an environment relevant to the subject
D) To provide an opportunity for intensive foreign language learning
E) To increase awareness of the student's role in his or her own culture


F) To achieve understanding of another culture

G) To encourage personal development

H) To broaden a liberal arts education

I) To increase cross-cultural sensitivity

J) To develop intercultural communication skills

Table IV C below will give the number of responses for each item A-J, along with the mean score, standard deviation, and range of scores.

\section{TABLE IV C}

MEAN RATINGS OF GOALS AND OBJECTIVES 6A-J

$\begin{array}{ccccc}\text { ITEM } & \text { N } & \text { MEAN } & \text { SD } & \text { RANGE } \\ \text { A } & 113 & 6.24 & 1.19 & 1-7 \\ \text { B } & 114 & 6.44 & 1.18 & 1-7 \\ \text { C } & 112 & 6.17 & 1.11 & 1-7 \\ \text { D } & 113 & 5.24 & 2.28 & 1-7 \\ \text { E } & 111 & 5.52 & 1.60 & 1-7 \\ \text { F } & 113 & 6.47 & 1.09 & 1-7 \\ \text { G } & 115 & 6.06 & 1.13 & 2-7 \\ \text { H } & 113 & 6.00 & 1.40 & 1-7 \\ \text { I } & 114 & 6.39 & 1.04 & 2-7 \\ \text { J } & 112 & 5.85 & 1.51 & 1-7\end{array}$

The last five goals in question six, K-0, were found in a 1955 study to be the most frequently expressed goals of study abroad programs by the institutions who sponsored them (Gullahorn and Gullahorn, 1958. p.369). These goals 1 is ted 
in order of their frequency in 1955 are:

K) To promote international understanding and good will among peoples of the world as a contribution to peace

L) To develop friends and supporters for the United States by giving persons from other countries a better understanding of the life and culture of the United States

M) To contribute to the economic, social, or political development of other countries

N) To aid in the educational or professional development of outstanding individuals

0) To advance knowledge throughout the world for the general welfare of mankind

Thirty years later, the study abroad program administrators who participated in this research survey felt these goals were not nearly as important as most of the other goals and objectives listed in this question. Four of these five goals received the lowest ratings of importance overall of all 15 goals and objectives in this study. Table IV D below illustrates this.

\section{TABLE IV D}

MEAN RATINGS OF 1955 GOALS OF SPONSORING INSTITUTIONS IN 1985

$\begin{array}{cccccr}\text { GOAL } & \text { N } & \text { MEAN } & \text { SD } & \text { RANGE } & \text { RANK } \\ \text { K } & 112 & 5.56 & 1.77 & 1-7 & 9 \text { th } \\ \text { L } & 113 & 4.46 & 1.91 & 1-7 & 13 \text { th } \\ \text { M } & 113 & 2.89 & 1.79 & 1-7 & 15 \text { th } \\ \text { N } & 113 & 5.07 & 1.82 & 1-7 & 12 \text { th } \\ 0 & 109 & 4.05 & 2.18 & 1-7 & 14 \text { th }\end{array}$




\section{CROSS-CULTURAL INVOLVEMENT}

The second section of the questionnaire was concerned with the program administrators perceptions of the importance of four different aspects of cross-cultural involvement. Responses to each were marked on a 1-7 likerttype scale.

The questions were:

1) "How important do you feel it is to incorporate coursework which focuses specifically upon the host culture into the curriculum?", "To what extent is this being accomplished?"

2) "How important do you feel it is for your program to encourage informal out-of-class experiences which may have educational value, as an integral part of the study abroad program?"

3) "How important do you feel it is to require students to do research assignments and field work which necessitate involvement in the host culture?"

4) "How important do you feel it is to utilize resources provided by the host environment to enrich the curriculum?"

The second part of each question 2-4 was: "To what extent is this being implemented?"

The mean ratings of the questions on cross-cultural involvement are listed below in Table IV $E$. 
TABLE IV E

MEAN RATINGS OF SECTION II: CROSS-CULTURAL INVOLVEMENT

$\begin{array}{cccccc}\text { QUESTION } & \text { PART } & \text { N } & \text { MEAN } & \text { SD } & \text { RANGE } \\ & & & & & \\ 1 & \text { IMPORTANCE } & 115 & 6.28 & 1.18 & 1-7 \\ 1 & \text { EXTENT } & 115 & 5.87 & 1.45 & 1-7 \\ & & & & & \\ 2 & \text { IMPORTANCE } & 115 & 6.36 & 0.86 & 3-7 \\ 2 & \text { EXTENT } & 115 & 5.91 & 1.16 & 2-7 \\ 3 & \text { IMPORTANCE } & 114 & 5.61 & 1.37 & 1-7 \\ 3 & \text { EXTENT } & 112 & 4.97 & 1.51 & 1-7 \\ 4 & \text { IMPORTANCE } & 114 & 6.53 & 0.84 & 2-7 \\ 4 & \text { EXTENT } & 114 & 6.03 & 1.19 & 1-7\end{array}$

III. ORIENTATION

The third section of the questionnaire used in this research project concerned the orientation of students in preparation for study abroad.

The first question asked program directors how important they felt it is to provide a cultural orientation. of 114 responses on the $1-7$ scale the mean rating was 6.41 , indicating that these program directors feel this type of orientation is very important. Nobody gave this question a response of 1 which would rate this type of orientation program not at all important. This made the range of scores six, from 2-7, and the standard deviation was 0.97 .

The second question asked if programs actually provided this type of cultural orientation training. Of 115 responses 102 or $89 \%$ said, Yes, their program provides this cultural orientation. 13 respondents or $11 \%$ said, No. 
The third question asked the 102 program directors who provide a cultural orientation when this orientation begins. Table IV F below shows the total number of responses for each item, and the percentage of possible responses out of 102. (Some respondents checked more than one response.)

\section{TABLE IV F}

NUMBER OF RESPONSES AND PERCENT OF TOTAL RESPONSES FOR QUESTION THREE

I TEM

6-12 months before departure 3-5 months before departure 1-2 months before departure 3-4 weeks before departure 1-2 weeks before departure less than one week before departure within one week of arrival abroad 2-3 weeks after arrival abroad other

The "other" responses included $\mathrm{N} \quad \%$ 27 26

$40 \quad 39$

22 21

$2 \quad 2$

2

11

27 26

$2 \quad 2$

3

orientation", and "individual orientation with faculty member (the) first five weeks abroad".

Question four of the orientation section asked: What forms does your orientation take? Respondents were asked to check all that apply. Table IV G below lists the individual response items, the number of responses for each item, and the percentage of possible answers out of 102 respondents. 
TABLE IV G

WHAT FORMS ORIENTATION PROGRAMS TAKE

FORM

an orientation handbook

a half day program or less

a one day program

an intensive weekend workshop

a series of weekend workshops

a series of weekly meetings

a week long workshop

an orientation course for credit

other
N $\quad \%$

$52 \quad 51$

$20 \quad 20$

98

98

$2 \quad 2$

$35 \quad 34$

44

$26 \quad 25$

$30 \quad 29$

Most notable "other" forms of orientation included: informal ta $1 \mathrm{ks}$ with returnees, mailings, readings, phone conversations, and local travel.

The fifth question of the orientation section was: who of the following are utilized as orientation resources? Respondents were asked to check all answers that apply. Table IV H below lists the individual response items, the number of responses for each item, and the percentage of possible responses out of 102 . 
TABLE IV H

WHO OF THE FOLLOWING ARE UTILIZED

AS ORIENTATION RESOURCES ?

\section{ITEM}

previous program directors

former student participants

students or faculty from the host country

experts in intercultural communication

experts in specific area studies

diplomats from the U.S. embassy

a study abroad adviser

other

$\mathrm{N} \%$

$63 \quad 62$

$84 \quad 82$

$52 \quad 51$

$38 \quad 37$

$47 \quad 46$

$5 \quad 5$

$64 \quad 63$

$13 \quad 13$

"Other" orientation resources 1isted for this question included a travel agent, and a financial adviser. An interesting "other" response was: "Students do research projects while abroad, and present their findings to prospective applicants the following year".

Question six asked program directors which teaching methods are significantly utilized in their orientation programs. Table IV I below lists the eight teaching methods used as reaction items in question six, the number of responses for each method, and the percentage of possible responses. Survey participants were asked to check all methods that apply. 
TABLE IV I

TEACHING METHODS UTILIZED IN

ORIENTATION PROGRAMS

$\begin{array}{lll}\quad \text { METHOD } & \text { N } & \% \\ \text { lectures } & 76 & 75 \\ \text { discussions } & 95 & 93 \\ \text { readings } & 60 & 59 \\ \text { simulations } & 10 & 10 \\ \text { role plays } & 11 & 11 \\ \text { case studies } & 15 & 15 \\ \text { critical incidents } & 23 & 23 \\ \text { audiovisuals } & 64 & 63\end{array}$

Question number seven asked: How important do you feel it is to evaluate the effectiveness of your cultural orientation program? Ratings were again on a scale of $1-7$, not at all important, to very important. There was a mean score of 5.97 from the 100 responses. The scores ranged from 1-7, and the standard deviation was 0.33. The second half of question seven asked: To what extent is evaluation of your cultural orientation program being implemented? A mean score of 4.49 was the result. There was a full range of scores including 9 responses out of 102 indicating this evaluation is not being implemented at a 11 . The standard devation was 1.91 .

Question number eight was comprised of 18 different items which came from the review of intercultural 
communication 1iterature. The question reads: To what degree is information on the following included in your orientation program, and/ or course curriculum? A likerttype scale "l" being not at al 1 , and "7" being to a great extent was placed after each item. Table IV J below lists each of the 18 intercultura 1 communication concepts, the number of respondents, mean scores, standard deviation, and the range of scores. 


\section{TABLE IV J}

MEAN SCORES FOR INTERCULTURAL COMMUNICATION CONCEPTS

\section{CONCEPT}

culture shock

stereotypes \& generalizations

ethnocentrism

tolerance of ambiguity

culture-based behavioral norms

values, assumptions \& beliefs

cultural self-awareness

awareness of host country culture

cultural relativity

multiculturality

perception

listening and feedback

difference in communication style

cultural adaptation

coping strategies

time orientations

ethics of cross-cultural encounters empathy
N MEAN SD RNG $100 \quad 5.14 \quad 1.76 \quad 1-7$

$\begin{array}{llll}101 & 4.88 & 1.66 & 1-7\end{array}$

$95 \quad 4.52 \quad 1.63 \quad 1-7$

$93 \quad 4.56 \quad 1.79 \quad 1-7$

$\begin{array}{llll}96 & 4.87 & 1.67 & 1-7\end{array}$

$\begin{array}{llll}98 & 5.29 & 1.48 & 1-7\end{array}$

$\begin{array}{llll}98 & 4.92 & 1.53 & 1-7\end{array}$

$\begin{array}{llll}98 & 5.94 & 1.26 & 1-7\end{array}$

$90 \quad 4.65 \quad 1.65 \quad 1-7$

$95 \quad 4.52 \quad 1.78 \quad 1-7$

$89 \quad 4.65 \quad 1.70 \quad 1-7$

$94 \quad 4.42 \quad 1.68 \quad 1-7$

$96 \quad 4.92 \quad 1.53 \quad 1-7$

$\begin{array}{llll}96 & 5.36 & 1.55 & 1-7\end{array}$

$96 \quad 5.04 \quad 1.64 \quad 1-7$

$89 \quad 4.28 \quad 1.82 \quad 1-7$

$90 \quad 4.28 \quad 1.70 \quad 1-7$

$92 \quad 4.66 \quad 1.64 \quad 1-7$

The last two questions of the orientation section are regarding re-entry orientation programs. Question number nine asks respondents how important they feel it is to offer re-entry orientation programs before, or soon after students 
return to the U.S. The mode score on the $1-7$ scale was 1 , with 27 respondents indicating they felt offering a re-entry orientation program was not at all important. There was a full range of scores with 21 respondents circling 7 , very important. The mean score from the 107 who responded was 3.89. The standard deviation was 2.27 .

Question 10 asked those who offer a re-entry program, to what degree do they include information on eleven common re-entry problems. The same 1-7 Likert-type scale was used with "l" being not at all, and "7" being to a great extent. Table IV K below lists each of the eleven common re-entry problems, the number of respondents, mean scores, standard deviation, and the range of scores. 55 people checked not applicable for this question. Many others skipped the entire section. 
TABLE IV K

MEAN SCORES FOR RE-ENTRY PROBLEMS

\section{PROBLEM}

re-entry shock

creative use of the foreign experience

reverse ethnocentrism

family problems

attitude changes

inappropriate independence

depression

value conflicts with family \& friends

jealousy

pressure to conform to pre-sojourn

behavior

inability to communicate the foreign experience to family \& friends
N MEAN SD RNG

$\begin{array}{llll}31 & 4.96 & 1.37 & 2-7\end{array}$

$\begin{array}{llll}32 & 5.40 & 1.10 & 3-7\end{array}$

$\begin{array}{llll}30 & 4.03 & 1.81 & 1-6\end{array}$

$\begin{array}{llll}29 & 3.89 & 1.71 & 1-7\end{array}$

$\begin{array}{llll}33 & 5.06 & 1.36 & 1-7\end{array}$

$31 \quad 2.45 \quad 2.63 \quad 1-6$

$35 \quad 4.54 \quad 1.70 \quad 1-7$

$\begin{array}{llll}35 & 4.11 & 1.81 & 1-7\end{array}$

$\begin{array}{llll}33 & 2.84 & 1.66 & 1-6\end{array}$

$\begin{array}{llll}34 & 3.47 & 1.58 & 1-6\end{array}$

$34 \quad 4.70 \quad 2.00 \quad 1-7$

\section{PROGRAM EVALUATION}

The final section of this four part questionnaire was on program evaluation. Question one asked: What provisions are made for program evaluation? Respondents were asked to check all responses given that apply. Question one 1 isted nine common methods of program evaluation, and a space to write in other provisions that program sponsors may make for evaluating their study abroad programs. Table IV L lists the nine reaction items for question one, the number of responses for each item, and the percentage of possible 
responses out of the 115 survey participants.

TABLE IV L

PROVISIONS MADE FOR PROGRAM EVALUATION

METHOD

$\mathrm{N}$

$\%$

students submit evaluation forms

98

85

faculty submit evaluation forms

50

43

student surveys/interviews

58

50

faculty surveys/interviews

26

23

evaluation by program leader

81

70

evaluation by advisory committee

31

27

institutional self-study

29

25

on-site evaluation by external

consultants

25

22

host country personnel involved

with program submit evaluations

28

24

other

6

5

Provisions written in under "other" included: visits of the study abroad director to sites, informal contacts with a random sample of former students, and "The final week is spent in small group discussions/evaluation of program and how to apply when one returns to (the) states".

The second question of the program evaluation section asks: Which of the following aspects of the program do evaluations focus on? There are six aspects listed that are commonly focussed on when evaluating study abroad programs. A space where other as pects could be written in was also 
provided. Table IV M below lists these aspects, the number of responses each item received, and the percentage of possible responses.

\section{TABLE IV M}

PROGRAM ASPECTS EVALUATIONS FOCUS ON

$\begin{array}{lrr}\text { ASPECT } & \text { N } & \% \\ \text { academic quality } & 109 & 95 \\ \text { logistic program support } & 80 & 70 \\ \text { student achievement } & 78 & 68 \\ \text { cross-cultural immersion } & 49 & 43 \\ \text { homestay experience } & 55 & 48 \\ \text { orientation } & 64 & 56 \\ \text { other } & 7 & 6\end{array}$

Most notable aspects written in as "other" program aspects were: responsiveness to student needs and concerns, and financial viability.

The third question asked survey participants, When is program evaluation done? Table IV N below lists five common times when study abroad programs are evaluated, the number of responses each item received, and the percentage of possible responses. 
TABLE IV N

WHEN PROGRAM EVALUATIONS ARE DONE

\begin{tabular}{lcc}
\multicolumn{1}{c}{ TIMES } & $\mathrm{N}$ & $\%$ \\
end of each term & 53 & 46 \\
end of final term & 25 & 22 \\
mid-year & 11 & 10 \\
soon after returning home & 54 & 47 \\
several months after returning home & 15 & 13 \\
other & 11 & 10
\end{tabular}

Other listed times programs are evaluated included, every month, every five years, longterm after ten years, and throughout the year on an ongoing basis.

The last question that used a 1-7 Likert-ty pe scale was question number four of this last section. The question was: How important do you feel it is to use the findings of the evaluation methods to effect indicated changes in the program plan? 52 participants out of 114 answered 7 , very important. Nobody answered with a 1 or 2 and just one person answered with a 3 . This equaled a mean score of 6.12 with a standard deviation of 0.97 . The second part of the question asked: To what extent are indicated changes actually made? 107 people answered this question. The responses ranged from 2-7. The mean score was 5.41, with a standard deviation of 1.23 .

Question five asked: Does your institution make program evaluations available to interested potential 
program participants? 57 people said Yes. 47 people said No, and 11 gave no response. One participant wrote in: "I suppose we would, but since 1971 nobody has asked."

Question number six asked participants if their institution formally endorses the 1981 NAFSA Principles for International Educational Exchange. 33 respondents or $29 \%$ said Yes. 6 respondents or $5 \%$ said No, and the majority of respondents 76 out of 115 or $66 \%$ said they don't know.

Question seven asked participants: Would you be willing to complete a questionnaire similar to this one a week or two from now? 72 particpants or $63 \%$ answered Yes. 38 participants or $33 \%$ answered No, and 5 people or $4 \%$ gave no response.

The final question asked for optional comments on the questionnaire or the topics themselves. Some of these comments will be discussed in the next chapter. 


\section{CHAPTER V \\ IMPLICATIONS, LIMITATIONS, DISTORTIONS, RELIABILITY STUDY AND SUMMARY \\ DISCUSSION OF IMPLICATIONS}

This first section will be a brief discussion of the data presented in the last chapter.

The first survey question which asked how the program's objectives are made known to students seems to indicate that most programs have found acceptable ways of making objectives known to their students. Only 7 respondents out of 115 checked the response in which program objectives are assumed to be understood by the students. Question 2 reveals that program directors feel it is very important to clearly state the goals and objectives of the study abroad program. However this is not al ways being implemented to a great extent. The third question indicated that respondents feel it is important to define and articulate expected outcomes of participating in the program, but this is not actually being accomplished to a great extent. One comment written in is probably representative of some of these discrepancies; ..."I have certain ideas of how things should be done, but I do not have the clout to change the system already in place. Thus 
the discrepancy in some of the two-part questions between what I feel and what is actually done."

Question number 4 reveals that it is felt to be important to insure that courses offered by U.S. faculty are modified to make use of the host country environment. This is being accomplished quite well in most cases.

Question number 5 concerning foreign language proficiency is perhaps dangerous to draw conclusions from because of programs in English speaking countries. Seventeen people chose the not applicable response because their programs were in an English speaking country. However, of those who responded to the question, it appears that language proficiency is relatively important to achieving their programs' objectives, and is an integral part of these programs.

Al 1 goals and objectives were rated very high until the last four which came from the Institute on International Education's 1955 study, which was discussed in chapter two. As mentioned in chapter four, four of these five goals received the lowest ratings of importance overall of all fifteen goals and objectives in the questionnaire. Table V A below will list once again the mean ratings and ranks of these goals. Table V B will list the highest rated goals and objectives of this study. 
TABLE V A

MEAN RATINGS OF 1955 GOALS OF SPONSORING INSTITUTIONS IN 1985

$\begin{array}{cccccr}\text { GOAL } & \text { N } & \text { MEAN } & \text { SD } & \text { RANGE } & \text { RANK } \\ \text { K } & 112 & 5.56 & 1.77 & 1-7 & 9 \text { th } \\ \text { L } & 113 & 4.46 & 1.91 & 1-7 & 13 \text { th } \\ \text { M } & 113 & 2.89 & 1.79 & 1-7 & 15 \text { th } \\ \text { N } & 113 & 5.07 & 1.82 & 1-7 & 12 \text { th } \\ 0 & 109 & 4.05 & 2.18 & 1-7 & 14 \text { th }\end{array}$

TABLE V B

MEAN RATINGS OF HIGHEST RATED

GOALS AND OBJECTIVES

$\begin{array}{cccccc}\text { GOAL } & \text { N } & \text { MEAN } & \text { SD } & \text { RANGE } & \text { RANK } \\ \text { F } & 113 & 6.47 & 1.09 & 1-7 & 1 \text { st } \\ \text { B } & 114 & 6.44 & 1.18 & 1-7 & 2 \text { nd } \\ \text { I } & 114 & 6.39 & 1.04 & 2-7 & 3 \mathrm{rd} \\ \text { A } & 113 & 6.24 & 1.19 & 1-7 & 4 \text { th } \\ \text { C } & 111 & 6.17 & 1.11 & 1-7 & 5 \text { th }\end{array}$

A few comments written in by survey participants on the 1955 goals included: "You've got to be kidding", "These are so global, one feels silly circling a number", and "aw come on". The low ratings coupled with comments such as these perhaps indicate that these goals reflect the ideals of a bygone era, and that priorities of program directors have changed some in thirty years.

Although a lot may have changed since 1955 , it is 
interesting to note that the highest rated goal in this study and the most frequently expressed goa 1 in 1955 both deal with international understanding. The highest rated goal which resulted from this study was to achieve understanding of another culture. The most frequently expressed goal in the 1955 study was to promote international understanding and good will among peoples of the world as a contribution to peace.

Goal M, "To contribute to the economic, social, or political development of other countries," received the lowest rating of a11 15 goals and objectives. 38 respondents gave this goal a rating of 1 (not at a 11 important). Rated 14 th was goa 10 , "To advance knowledge throughout the world for the general welfare of mankind." 22 respondents out of 109 rated this goal with a 1 (not at a11 important).

Section number 2 on cross-cultural involvement indicates that only one aspect is not being implemented to a great extent. Requiring students to do research assignments and field work which necessitate involvement in the host culture received a mean score of only 4.97 .

Section number 3 on orientation indicates strong support in favor of cultural orientation programs. $89 \%$ of survey participants indicated that their programs do provide this type of orientation. The most common time to start orientation programs is $3-5$ months before departure. The 
most common form of orientation is orientation handbooks, the second most common form being a series of weekly meetings. Former student participants and previous program directors are utilized most of ten as orientation resources. Discussions, lectures and audiovisuals are the most common teaching methods respectively in orientation programs.

Evaluating the effectiveness of orientation programs is not being implemented to a great extent, although the importance of doing so received a mean score of 6 ; indicating relatively high importance.

Question number 8 of this section reveals there is a strong emphasis on the host culture in orientation programs. out of 18 reaction items that could be included in or ientation programs, the four which were included to the greatest extent were: 1) a wareness of host country culture, 2) cultural adaptation, 3) cultural values, assumptions, and beliefs, and 4) culture shock.

The pattern of responses on this question seems to indicate that study abroad programs are placing more emphasis on the "culture specific" aspects of a sojourn such as items 1-3 above, than on the "culture general" aspects such as culture shock. Culture specific training involves the analysis of the host country in which students will live. Culture general training deals with the types of issues that face all sojourners wherever they may be (Brislin \& Pedersen, 1976). 
Question number 9 which asked about the importance of offering a re-entry program, received surprisingly low ratings of importance. 27 out of 107 respondents gave this question a 1 rating, or not at all important. The mean score was only 3.89. Only 35 out of 115 respondents answered question number 10 which asked, "If a re-entry program is offered, to what degree is information on the following included?" The four responses which were offered to the greatest degree were, in order: 1) creative use of the foreign experience, 2) attitude changes, 3) re-entry shock, 4) inability to communicate the foreign experience to family and friends. The low overall response to question number 10 , and the limited number of elements noted by those who did answer, may indicate that re-entry programs are not receiving as much attention in the field as they are in the professional organizations.

The data from the final section on program evaluation indicates that the most common provisions for program evaluation are students submitting evaluation forms and evaluation by the program leader. Evaluations most commonly focus on academic quality, followed by logistic program support and student achievement. Most programs are evaluated soon after returning home or at the end of each term. The fourth question of this section indicates that although program directors feel it is important to use the findings of evaluations to make changes in future programs, 
this is not actually happening to a great extent.

NAFSA might be surprised to discover that on 1 y $29 \%$ of institutions surveyed said their institutions formally endorse the NAFSA Principles for International Educational Exchange that were discussed in chapter two. $5 \%$ said their institutions do not endorse these Principles, and $66 \%$ said they didn't know if their institution formally endorses the Principles or not. 


\section{LIMITATIONS OF THE STUDY}

As with any type of survey research there were some limitations in this project. The limitations stem primarily from the survey instrument. Many of these limitations were illuminated by the optional comments written in at the end of the questionnaire. Comments included "1-7 scale not best suited for this" and "the number rating system distorts the relative importance/non-importance of the elements". The numbering system may well be a limitation. However this Likert-type scale system is very common in survey research and seems we11 within the norm. George Renwick (1981) points out ..."the methods of social science are not precise, nor are the numbers which result; the numbers often suggest an accuracy which they do not possess." (p.251) It is also important to note that these numerical scales are not intended to measure actual practices within study abroad programs. What is being measured is program directors' perceptions of what is happening within their study abroad programs.

Another 1 imitation voiced by two of the survey participants was that "the questionnaire seems geared toward programs which take students from their own institution abroad." If students go abroad through other institutions the survey respondent might not have been aware of the 
specific program aspects asked about in the questionnaire. To control this problem every attempt was made in the cases of consortia and cosponsorships to mail the questionnaire to the institution which actually administers the program. It was not the intention of this study to measure effectiveness, but rather to identify what types of orientation programs and evaluations are being conducted. It should be noted however, that this study does not provide any information as to how effective these methods are. 


\section{POSS IBLE DISTORTIONS OF INFORMATION}

In a survey like the one undertaken for this study, it is difficult to completely eliminate all possible distortions of information. The main source of possible distortion in this study stems from respondent bias. There can be distortions in behavior that occur when people know they are the subjects of a study. These are known as Hawthorne effects (Roethlisberger \& Dickson, 1939). Because of this, respondents may have been more inclined to give responses which they perceive to reflect social desirability. High ratings may have occurred to some degree from leniency, a reluctance to rate oneself at the low end of any scale. Consequently the results may be somewhat skewed. Efforts were made to control this problem by assuring respondents complete anonymity. No connection was or will be made between the data and who provided it. Therefore there was theoretically no reason to misrepresent the information provided. However, many respondents chose not to remain anonymous and voluntarily wrote their names and addresses on the surveys, and/or the return envelopes.

On some questions where participants checked "a11 that apply" there could be two responses for the same thing. An example might be an orientation course for credit which is a series of weekly meetings. 


\section{THE RELIABILITY STUDY}

Of the 115 respondents who returned usable questionnaires, 72 indicated they would be willing to complete another questionnaire. A random sample of 25 of these people were retested. 14 of the retest questionnaires were returned.

To determine the reliability of the instrument, the responses given on the 1-7 scales were recorded for each respondent both times they completed the questionnaire. To determine the variance between the two tests, the Pearson product-moment correlation coefficient (Pearson r) was computed for each 1-7 scale. A Pearson $r$ was also computed for each of the four sections overall, and for the questionnaire instrument as a whole.

There were a total of 55 questionnaire items which utilized the 1-7 scales. Of these, 22 questions were found to be significant at the $p<.0011$ evel. 14 were found to be significant at the $p<.01$ level. 2 questions were found to be significant at the $p<.02$ level. 8 questions were significant at the $p<.05$ level. These 46 questionnaire items have strong correlations. The remaining 9 did not do as we11. 6 questions were found to be significant at the $p<.10$ level, and three had zero correlations of $p>.10$.

The three items found to have zero correlation were 
from the orientation section, question number 8 . The question asks, "To what degree is information on the following included in your orientation program, and/or course curriculum?" The three items were: multiculturality, cultural relativity, and cultural values, assumptions, and beliefs. The inconsistency in the test-retest scores on the item cultural values, assumptions, and beliefs may stem from the fact that the item fails to specify whether or not the values, assumptions and beliefs inquired about are those of the home culture, or of the host culture. This oversight could have been a source of ambiguity. The terms multiculturality and cultural relativity may have been confusing to some, resulting in the zero correlation.

Four of the six items which were only significant at the p<.10 level were also from this same question. They were: ethnocentrism, cultural self-awareness, awareness of host country culture and time orientations. The other two items came from the last section question 4, parts one and two. The question reads, "How important do you feel it is to use the findings of the evaluation methods to effect indicated changes in the program plan? To what extent are indicated changes actually made?"

The nine items receiving low significance levels all came towards the end of the questionnaire. Of the 55 1-7 scale items, the first 36 all had significance levels of $<.05$ or better; most being better. The final 19 1-7 scales 
contained all 9 of the correlations at the $<.10$ level or the $>.10$ level. Perhaps this decline in reliability towards the end of the survey was due to fatigue, boredom or time constraints.

The first three sections of the questionnaire; Goals and objectives, Cross-cultural involvement and Orientation; received overall significance levels of $p<.001$. The final section on program evaluation, as a whole, was found to be significant at the $p<.01$ level. The Pearson $r$ computed for the questionnaire as a whole was found to be significant at the $p<.001$ level. (See Appendix D for a complete list of Pearson r's and significance levels).

This test-retest reliability study has shown the questionnaire to be a consistent, reliable measuring device with the limitations noted, and thus did not represent in itself a major limitation of the study. 


\section{IMPLICATIONS FOR FUTURE RESEARCH}

This study has collected data which helps to develop a clearer picture of the degree to which U.S. collegesponsored study abroad programs are following guidelines that have been determined to be important criteria to include in study abroad programs. The goals and objectives of study abroad programs are also more clearly identified. As a result of this study we now have a better idea of the degree to which intercultural communication concepts are being included in these study abroad programs.

Now that a picture of the present state of affairs is complete, future research could evaluate these prevailing trends, isolate problem areas, and suggest ways to improve the situation. Future research could also attempt to discover how effective the various orientation programs and evaluation methods are.

One of the most interesting findings of this study is the discrepancy between the professional organizations and study abroad program directors concerning the importance of re-entry orientation programs. Future research could attempt to isolate the reason(s) behind this discrepancy. 


\section{SUMMARY AND CONCLUSIONS}

This research project has shown that, in general, program administrators agree with professional study abroad organizations regarding what aspects are important to include in their programs. In most cases guidelines are not being implemented to as great of a degree as program directors would like. Program directors do not find reentry orientation programs nearly as important as the professional organizations do.

It is hoped that the survey participants were able to derive some usefulness for their own programs by completing the survey. One comment made by a survey participant leads me to believe this may have occurred to some degree. This respondent wrote: "In five years of activity our record seems pretty good. You have however, given us some things to consider."

It is my hope that in a small way this research project will help to advance the study abroad field. Through properly run study abroad programs, I believe a significant contribution to world peace can be made. 


\section{SELECTED BIBLIOGRAPHY}

Abrams, Irwin. (1960). Study Abroad: New Dimensions in Higher Education, \#6. Washington, DC: U.S. Government Printing Office.

Abrams, Irwin \& Heller, Francis. (1978). Evaluating $\frac{\text { Academic Programs Abroad: The CIEE Project. }}{\text { (Occasional paper No.21)., New York, NY: Council }}$ on International Educational Exchange.

Adler, Peter. (1979). Beyond cultural identity: Reflection upon cultural and multicultural man. In Brislin, Richard W., Culture Learning Concepts, Application and Research. Honolulu, HI: University of Hawii Press.

ANTFOSA, The Task Force on Study Abroad. (1979). Study Abroad Programs: An Evaluation Guide. Washington, DC: American Association of Collegiate Registrars and Admissions Officers, and the National Association for Foreign Student Affairs.

Barnlund, Dean C. The cross-cultural arena: An ethical void. In Larry A. Samovar and Richard E. Porter's (Eds.), Intercultural Communication: A Reader. Belmont, CA: Wadsworth Publishing Co., 1982, 378-383.

Bennett, Janet M. (1984). Intercultural Communication Training in Cultural Self-Awareness for Study Abroad. Unpublished doctoral dissertation, University of Minnesota.

Bennett, Milton J. Overcoming the Golden Rule: Sympathy and Empathy. In D. Nimmo (Ed.), Communication Yearbook 3. New Brunswick, New Jersey: TransactionInternational Communication Association, 1979, 407422 .

Bowman, John E. (1980, February). The evaluation of overseas educational programs. Taking measure of undergraduate study abroad, research and evaluation. Symposium conducted by the International Studies Association, Washington, DC. 
Brislin, Richard W., \& Pedersen, Paul. (1976). CrossCultural Orientation Programs. New York, NY: Gardner Press, Inc.

Brislin, Richard W. (1981). Cross-Cultural Encounters Face to Face Interaction. Pergamon General Psychology Series, vol. 94. New York, NY: Pergamon Press.

Carroll, Laverne. (1974, Spring). 01d problems and new meanings. Learning Today, Vol. 7 No. 2

(ERIC Document Reproduction Service No. EJ 098230 IR 500585 ).

CIEE. A Guide to Institutional Self-Study and Evaluation of Educational Progams Abroad. (1965). New York, NY : Council on International Educational Exchange.

Coelho, George V. (1962). Personal growth and educational development through working and studying abroad. Journal of Social Issues, 18,1 .

Cohen, Gail A., \& D'Angelo, Diane, (Eds.), U.S. CollegeSponsored Programs Abroad: Academic Year. The Learning Traveler Vol. 1.14 th ed. 3 vols. New York, NY: Institute of International Education, 1984.

Connotillo, Barbara Cahn., \& Feiger, Mindy, (Eds.). (1982). Basic Facts on Foreign Study. New York, NY: Institute of International Education.

Council on Postsecondary Accreditation. The Balance Wheel for Accreditation. (1984). Washington DC.

Gove, Philip Babcock. (Ed). (1967). Webster's Third New International Dictionary of the English Language. Springfield, Mass. G \& C Merriam Co.

Gullahorn, John T., \& Gullahorn, Jeanne E. (1958, Oct.). American objectives in study abroad. Journal of Higher Education, vol. XXIV 369-374.

Gullahorn, John T., \& Gullahorn, Jeanne E. (1966, Nov.). American students abroad: Professional versus personal development. The Annals of the American Academy of Political and Social Science, vol. 368, 4359 .

Harvey, 0.; Hunt, D.; \& Schroder, H. (1961). Conceptual Systems and Personality Organization. New York, NY: Wiley, 1961 . 
Haskins, Ch. H., (1923). The Rise of Universities. New York, NY: Holt and Co.

Hoopes, David S. Intercultural communication concepts and the psychology of intercultural experience. In Margaret D. Pusch's (Ed.), Mu1ticultural education: A cross-cultural approach. Chicago, Il: Intercultura1 Press, Inc., 1981, 9-38.

Hoopes, David S. \& Pusch, Margaret D. Definition of terms. In Margaret D. Pusch's (Ed.), Multicultural education: A cross-cultural approach. Chicago, Il: Intercultura1 Press, Inc., 1981, 1-8.

Howe11, W.S. Ethics of intercultural communication. Paper presented to the Speech Communication Association, Anaheim, Ca., November 1981 .

Hul1, W. Frank, IV, \& Lemke, Wa1ter H., Jr. (1975). The Assessment of off-campus higher education. Internationa1 Review of Education XXI, 2, 195-206.

Hu11, W. Frank, IV; Lemke, Walter H.,Jr., \& Haong, Richard Ting-Ku. (1977). The American undergraduate offcampus and overseas: A study of the validity of such programs: (Occasional paper No.20)., New York, NY: Council on International Educational Exchange.

Klassen, Frank H., Imig, David G., \& Iff, Joost. The International Dimension of American teacher education. Washington DC: AACTE. 1972, p.38

Koh1s, Robert L. (1979). Surviva1 Kit for Overseas Living. Chicago, IL: Intercultural Network/SYSTRAN Publications.

Lin, Nan. Foundations of Social Research. (1976). New York, NY: McGraw-Hi11 Book Company p.241

Littlejohn, Stephen W. (1983). Theories of Human Communication. Belmont, CA: Wadsworth Publishing Co., Inc.

Mandel baum, David, G. (1956). Comments. Journal of Social Issues, Vol.1, No.2 (1), 45-51.

Marion, P.B. Evaluation of Study Abroad. Paper presented at the meeting of the National Association for Foreign Student Affairs, Albuquerque, May 1974. (ERIC Document Reproduction Service No. ED 089634). 
McLuhan, Marshall. Understanding Media: Extensions of Man. New York: McGraw-Hill, 1964.

Mishler, Anita L. (1965). Personal contact in international exchanges. In Kelman, Herbert C. (Ed.). Internationa1 Behavior. New York, NY: Holt, Rinehart, \& Winston.

NAFSA. Study Abroad: Handbook for Advisers and administrators. (1979). Washington, DC.

NAFSA. NAFSA Policy Statement on International Education Exchange. (1980). Washington DC.

NAFSA. Standards and Responsibilities in International Educational Interchange. (1981). Washington, DC.

NAFSA. Principles for International Educational Exchange (1981). Washington, DC.

NAFSA. NAFSA Self-Study Guide. (1983). Washington, DC.

Northwest Association of Schools and Colleges. Accreditation Handbook. (1984). Seattle, WA.

Paige, R. Michael, \& Martin, Judith N. (1983). Ethical Issues and Ethics in Cross-cultural Training. In Landis, Dan \& Brislin, Richard W., Handbook of Intercultural Training, Vol.I. New York, NY: Pergamon Press.

Pearce, W. Barnett, \& Cronen, Vernon. Communication Action and Meaning. New York, NY: Praeger, (1980).

Pusch, Margaret D. (Ed.). (1981). Multicultural Education: A Cross-cultural Training Approach. Chicago, IL: Intercultural Press, Inc.

Renwick, George W. Evaluation: Some practical guidelines. In Margaret D. Pusch's (ed.), Multicultural education: A cross-cultural approach. Chicago, Il: Intercultura1 Press, Inc., 1981, 205-255.

Roeth1isberger, F.J. \& Dickson, M.J. (1939). Management and the Worker. Cambridge, MA: Harvard University Press.

Samovar, Larry, \& Porter, Richard. (1976) Communicating Interculturally. In Intercultural Communication: A Reader, 2 nd ed. Belmont, CA: Wadsworth Publishing Co. $4-38$ 
Sanders, Irwin T., \& Ward, Jennifer C. (1970). Bridges to Understanding: International Programs of American Colleges and Universities. New York, NY: McGraw-Hill Book Co.

Scott, W. Psychological and Social Correlates of International Images. In H. Kelman (Ed.). International Behavior: A Social Psychological Analysis. New York, NY: Holt, Rinehart, and Winston, (1965).

Seelye, H., \& Wasilewski, J. Toward a taxonomy of coping strategies used in multicultural settings. Paper presented at the meeting of The Society for Intercultural Education, Training, and Research. Mexico City, March 1979.

Singer, Marsha11 R. Culture: A Perceptual Approach. In Larry A. Samovar and Richard E. Porter's (Eds.), Intercultural Communication: A Reader. Belmont, CA.: Wadsworth Publishing Co., (1976). 110-119.

Smith, P.C., \& Kendal, L.M., (1963). Retranslation of Expectations: An Approach to the Construction of unambiguous anchors for rating scales. In Journal of Applied Psychology Vol. 47, 149-155.

Spector, Paul E. Research Designs Series: Quantitive Applications in the Social Sciences, Beverly Hills, CA., London, England. Sage Publications, (1981).

Stewart, Edward C. (1972). American Cultural Patterns: A Cross-cultural Perspective. Pittsburg, PA: Intercultural Communications Network, University of Pittsburg.

Triandis, H. Interpersonal Behavior. Monterey, CA: Brooks/Cole, (1977).

Tucker, Raymond K., Weaver, Richard L. III, Berryman-Fink, Cynthia. Research in Speech Communication. Englewood Cliffs, New Jersey. Prentice-Ha11, Inc., (1981).

Wa1den, J.W.H., (1909). The Universities of Ancient Greece. New York, NY: Charles Scribners.

Wasilewski, Jacqueline H., \& Seelye, H., Ned Historical Development of Multicultural Education. In Margaret D. Pusch's (Ed.), Multicultural Education a Crosscultura1 Approach. Chicago, I1: Intercultural Press, Inc. (1981), 39-61. 


\section{APPENDIX A}

\section{THE SURVEY QUESTIONNAIRE}

Please answer the following questions as accurately as you can. Please check the appropriate space(s), or circle the appropriate number on the continuum.

\section{GOALS and OBJECTIVES}

1) How are your program's objectives made known to students? (check all that apply)

- They are stated in the printed materials
- They are discussed during orientation
- They are discussed during personal interviews
- They are assumed to be understood by the students
other

2) How important do you feel it is for your institution to clearly state the goals and objectives of the study abroad program? $\begin{array}{llllllll}\text { not at all } & 1 & 2 & 3 & 4 & 5 & 6 & 7\end{array}$ very important To what extent is this policy (if any) being implemented? not at all $1 \begin{array}{llllllll} & 2 & 3 & 4 & 5 & 6 & 7 & \text { to a great extent }\end{array}$

3) How important do you feel it is to define and articulate the expected outcomes of participating in your program for prospective students?

not at all $1 \begin{array}{lllllll} & 2 & 3 & 4 & 5 & 6 & ?\end{array}$ very important To what extent is this being accomplished? not at all $1 \begin{array}{llllllll}1 & 2 & 3 & 4 & 5 & 6 & 7\end{array}$ to a great extent

4) How important do you feel it is to insure that courses offered by U.S. faculty are modified to make use of the host culture environment?

not at all $1 \begin{array}{llllllll} & 2 & 3 & 4 & 5 & 6 & 7 & \text { very important }\end{array}$ To what extent is this being accomplished?

not at all $1 \begin{array}{llllllll}1 & 2 & 3 & 4 & 5 & 6\end{array} \quad$ to a great extent

5) How important is foreign language proficiency in achieving your program's objectives?

N/A (eg: England programs)

not at all $\quad \begin{array}{llllllll}1 & 2 & 3 & 4 & 5 & 6 & 7 & \text { very important }\end{array}$

To what extent is foreign language learning an integral part of the program?

not at all $1 \begin{array}{llllllll} & 2 & 3 & 4 & 5 & 6 & 7\end{array}$ to a great extent

6) How important are the following goals and objectives for your program?

A) To integrate cross-cultural learning with academic learning not at all $\begin{array}{llllllll}1 & 2 & 3 & 4 & 5 & 6 & 7\end{array}$ very important 
B) To create unique study opportunities which are not available in the United States

not. at all $1 \begin{array}{llllllll} & 2 & 3 & 4 & 5 & 6 & 7 & \text { very important }\end{array}$

C) To stimulate academic achievement in an environment relevant to the subject

not at all $1 \quad \begin{array}{llllllll}2 & 3 & 4 & 5 & 6 & 7 & \text { very important }\end{array}$

D) To provide an opportunity for intensive foreign language learninz not at all $1 \begin{array}{llllllll} & 2 & 3 & 4 & 5 & 6 & 7 & \text { very important }\end{array}$

E) To increase awareness of the student's role in his or her own culture

not at all $1 \begin{array}{lllllll}1 & 2 & 3 & 4 & 5 & 6 & 7\end{array}$ very important

F) To achieve understanding of another culture not at all $1 \begin{array}{lllllll}1 & 2 & 3 & 4 & 5 & 6 & 7\end{array}$ very important

G) To encourage personal development not at all $\quad \begin{array}{llllllll}1 & 2 & 3 & 4 & 5 & 6 & ?\end{array}$ very important

H) To broaden a liberal arts education not at all $1 \begin{array}{lllllll}1 & 2 & 3 & 4 & 5 & 6 & 7\end{array}$ very important

I) To increase cross-cultural sensitivity (to increase program participants' ability to recognize and respect differing cultural characteristics)

not at all $1 \begin{array}{llllllll} & 2 & 3 & 4 & 5 & 6 & 7 & \text { very important }\end{array}$

$J)$ To develop intercultural communication skills (to increase program participants' ability to communicate effectively in other cultures)

not at all $1 \begin{array}{llllllll} & 2 & 3 & 4 & 5 & 6 & 7 & \text { very important }\end{array}$

K) To promote international understanding and good will among peoples of the world as a contribution to peace not at all $\quad \begin{array}{lllllll}1 & 2 & 3 & 4 & 5 & 6 & 7\end{array}$ very important

L) To develop friends and supporters for the United States by giving persons from other countries a better understanding of the life and culture of the United States

not at all $1 \begin{array}{llllllll} & 2 & 3 & 4 & 5 & 6 & 7 & \text { very important }\end{array}$

M) To contribute to the economic, social, or political development of other countries not at all $1 \begin{array}{llllllll} & 2 & 3 & 4 & 5 & 6 & 7 & \text { very important }\end{array}$

N) To aid in the educational or professional development of outstanding individuals
$\begin{array}{lllllllll}\text { not at all } & 1 & 2 & 3 & 4 & 5 & 6 & 7 & \text { very important }\end{array}$

$0)$ To advance knowledge throughout the world for the general welfare of mankind

not at all $1 \begin{array}{llllllll} & 2 & 3 & 4 & 5 & 6 & 7 & \text { very important }\end{array}$ 


\section{CROSS-CULTURAL INVOLVEMENT}

1) How important do you feel it is to incorporate coursework which focuses specifically upon the host culture into the curriculum?

$$
\text { not at all } 1 \begin{array}{llllllll} 
& 2 & 3 & 4 & 5 & 6 & 7 & \text { very important }
\end{array}
$$

To what extent is this being accomplished?

$$
\text { not at all } 110 \begin{array}{lllllll} 
& 2 & 3 & 4 & 5 & 6 & 7
\end{array} \text { to a great extent }
$$

2) How important do you feel it is for your program to encourase informal out-of-class experiences which may have educational value, as an integral part of the study abroad program? not at all $\begin{array}{llllllll}1 & 2 & 3 & 4 & 5 & 6 & ?\end{array}$ very important

To what extent is this being implemented? not at all $1 \quad \begin{array}{llllllll} & 2 & 3 & 4 & 5 & 6 & 7\end{array}$ to a great extent

3) How important do you feel it is to require students to do research assignments and field work which necessitate involvement in the host culture?

$$
\text { not at all } 1 \begin{array}{llllllll} 
& 2 & 3 & 4 & 5 & 6 & 7 & \text { very important }
\end{array}
$$

To what extent is this being implemented?

not at all $1 \begin{array}{llllllll} & 2 & 3 & 4 & 5 & 6 & 7 & \text { to a great extent }\end{array}$

4) How important do you feel it is to utilize resources provided by the host environment to enrich the curriculum?

$$
\begin{array}{lllllllll}
\text { not at all } & 1 & 2 & 3 & 4 & 5 & 6 & 7 & \text { very important }
\end{array}
$$

To what extent is this being implemented?

not at all $1 \quad 2 \quad 3 \quad 4 \quad 5 \quad 6 \quad ?$ to a great extent

\section{ORIENTATION}

1) Besides informational instructions concerning such logistics as payments, passports, visas, transportation, etc.., how important do you feel it is to provide a cultural orientation? $\begin{array}{lllllllll}\text { not at all } & 1 & 2 & 3 & 4 & 5 & 6 & 7 & \text { very important }\end{array}$

2) Does your program provide a cultural orientation?

- Yes (Please answer questions 3-8)

3) When does your program's orientation begin? 6-12 months before departure

- 3-5 months before departure

- 1-2 months before departure

- 3-4 weeks before departure 1-2 weeks before departure less than one week before departure 
within one week of arrival abroad

2-3 weeks after arrival abroad

other

4) What forms does your orientation take?

(check all that apply)

an orientation handbook

a half day program or less

a one day program

_ an intensive weekend workshop

- a series of weekend workshops

_ a series of weekly meetings

_ a week long workshop

- an orientation course for which credit is given

other

5) Who of the following are utilized as orientation resources?

(check all that apply)

$$
\text { previous program directors }
$$

former student participants

foreign students $\& /$ or visiting faculty from the host country

faculty with expertise in intercultural communication

faculty with expertise in specific area studies

diplomats from the host culture's U.S. embassy

a study abroad adviser

other

6) Which of the following teaching methods are significantly

utilized in your orientation program?

(check all that apply)

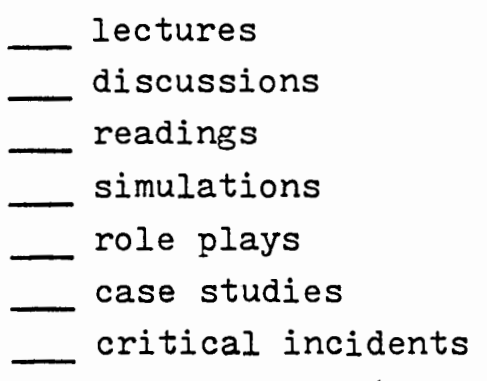
audiovisuals (films, videotapes, etc.)

7) How important do you feel it is to evaluate the effectiveness of your cultural orientation program?

not at all $1 \begin{array}{llllllll} & 2 & 3 & 4 & 5 & 6 & 7 & \text { very important }\end{array}$ 
To what extent is evaluation of your cultural orientation program being implemented?

not at all $1 \begin{array}{llllllll} & 2 & 3 & 4 & 5 & 6\end{array} ?$ to a great extent

8) To what degree is information on the following included in your orientation program, and/or course curriculum?

(not at all $1 \begin{array}{llllllll} & 2 & 3 & 4 & 5 & 6 & 7 & \text { to a great degree) }\end{array}$

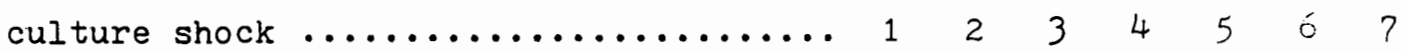

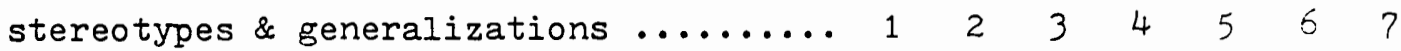

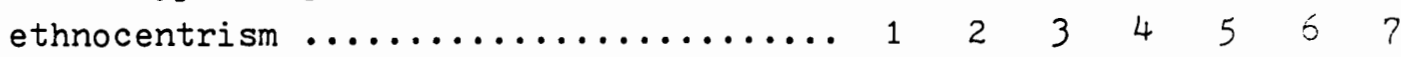

tolerance of ambiguity .................. 1234456 ?

culture-based behavioral norms ......... $123 \quad 3 \quad 4 \quad 5 \quad 6$ ?

cultural values, assumptions, \& beliefs $\begin{array}{lllllll}1 & 2 & 3 & 4 & 5 & 6\end{array}$ ?

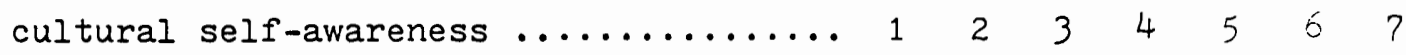

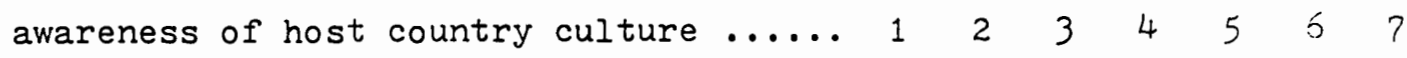

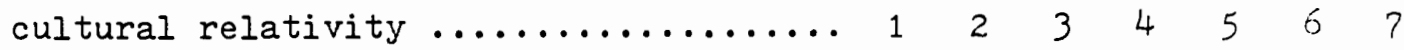

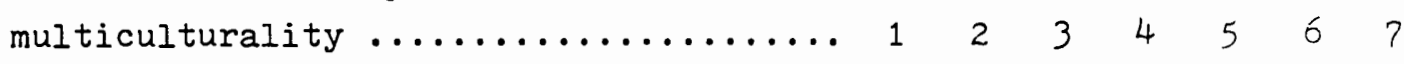

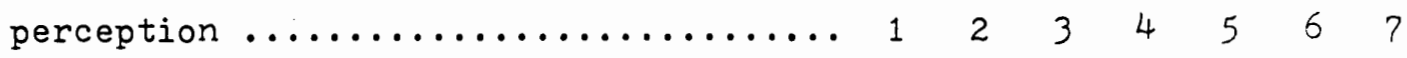

listening and feedback ................ 12234456 ?

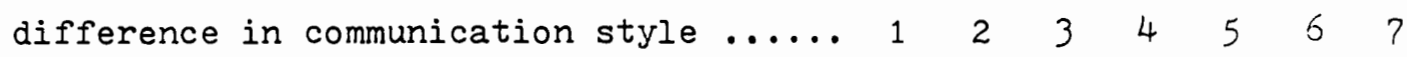

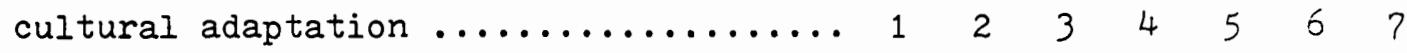

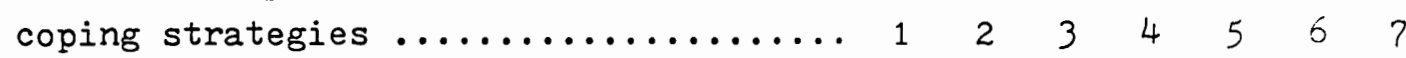

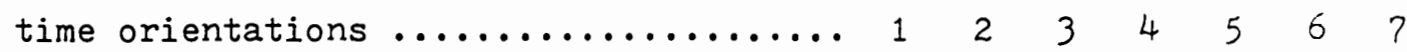

the ethics of cross-cultural encounters $1 \begin{array}{lllllll}1 & 2 & 3 & 4 & 5 & 6\end{array}$ ?

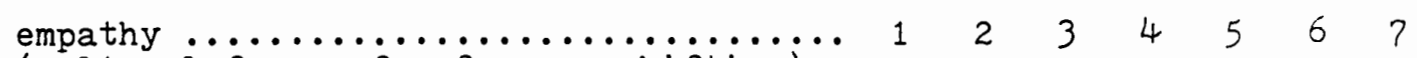

(cultural frame of reference shifting)

other

$\begin{array}{lllllll}1 & 2 & 3 & 4 & 5 & 6 & 7\end{array}$

9) How important do you feel it is to offer a re-entry orientation program before or soon after your students return to the U.S.?

not at all $\begin{array}{lllllllll}1 & 2 & 3 & 4 & 5 & 6 & 7 & \text { very important }\end{array}$

10) If a re-entry program is offered, to what degree is information on the following included? $\mathrm{N} / \mathrm{A}$

re-entry shock ........................ 123456

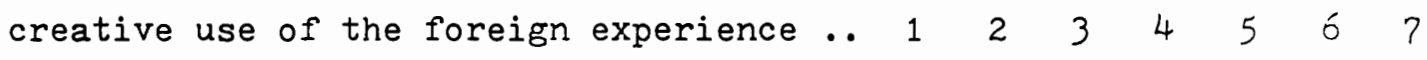

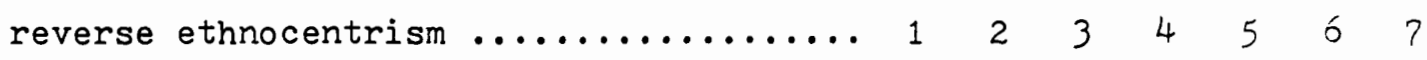

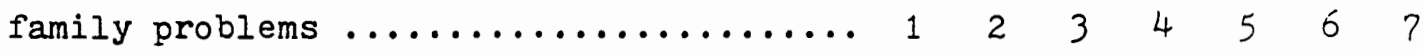

attitude changes ..................... 123456 ? 


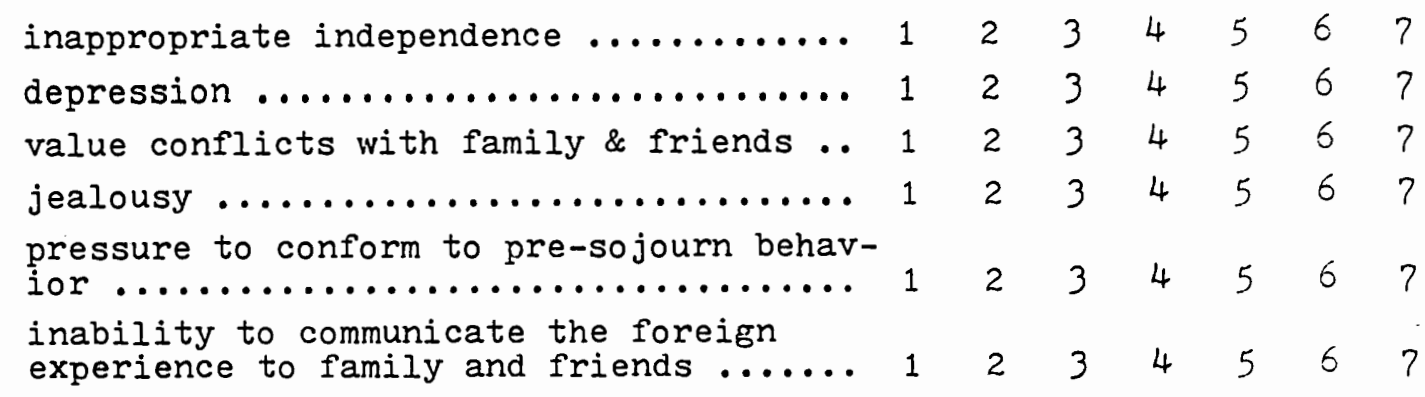

IV. PROGRAM EVALUATION

1) What provisions are made for overall program evaluation?

(check all that apply)

students submit evaluation forms

faculty submit evaluation forms

student surveys/interviews

faculty surveys/interviews

evaluation by program leader

evaluation by an advisory committee

institutional self-study

on-site evaluation by external consultants

host country personnel involved with program submit evaluations other

2) Which of the following aspects of the program do evaluations

focus on?

academic quality

logistic program support

student achievement (grades or other measures of achievement)

cross-cultural immersion

homestay experience

orientation

other

3) When is program evaluation done?

end of each term

end of final term

mid-year

soon after returning home

several months after returning home

other 
4) How important do you feel it is to use the findings of the evaluation methods to effect indicated changes in the prograin plan?

$$
\text { not at all } 1 \begin{array}{llllllll}
1 & 2 & 3 & 4 & 5 & 6 & 7
\end{array} \text { very important }
$$

To what extent are indicated changes actually made?

$$
\text { not at all } \begin{array}{llllllll} 
& 2 & 2 & 3 & 4 & 5 & 6 & ?
\end{array} \text { to a great extent }
$$

5) Does your institution make program evaluations available to interested potential program participants?

Y Yes

No

6) Does your institution formally endorse the 1981 NAFSA Princiries for International Educational Exchange?

Yes
No
don't know

7) Would you be willing to complete a questionnaire similar to this one a week or two from now?

$$
\text { __ Yes }
$$

8) Optional comments on the questionnaire or the topics themselves 


\section{APPENDIX B}

\section{PIIOT STUDY COVER IETTER}

COLLECE OF

LIBERAL ARTS AND SCIENCES

DEPARTMENT OF

SPEECH COMMUNICATION

COMMUNICATION STUDIES AREA

March 15, 1985
PORTLAND

STATE

UNIVERSITY

P.O. BOX 751

PORTLAND, OREGON

97207

503/229-3531

Dear

Enclosed is a copy of a questionnaire I have created as part of the thesis project I am doing at Portland State University under the direction of Dr. Milton Bennett.

I am currently running a pilot study and thus would appreciate it if you would look the quetionnaire over. Any comments or criticisms you care to make about the questionnaire's design, content, or other problems you foresee would be much appreciated.

Most of the questions have been compiled using standards of performance and guiding principles of good practice established and endorsed by professional organizations concerned with study abroad, including NAFSA, CIEE, and IIE. The other questions stem from relevant intercultural communication theory.

This project has been designed to assess the extent to which program administrators agree with the importance of these guidelines and perceive their programs to be operating according to them. The study will also assess the degree to which educational institutions are incorporating relevant intercultural communication training into their study programs abroad.

The questionnaire will be mailed to a random sample of the 946 U.S. college-sponsored study abroad programs listed by IIE in 1984. I will compile the information gathered into a descriptive assessment of the prevailing practices in the study abroad industry.

Due to impending deadlines your feedback would be most helpful if received by no later than Friday March 29.

Thank you for your time and concern in this matter.

Sincerely,

Thomas Bacheller

Milton J. Bennettoph.0.

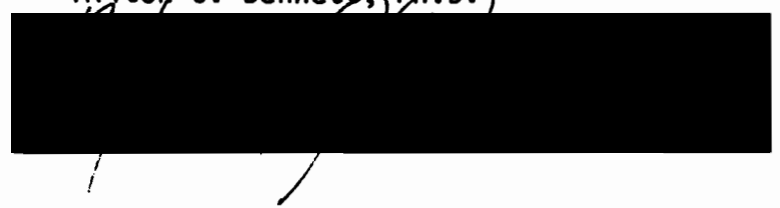


COLLEGE OF

LIBERAL ARTS AND SCIENCES

DEPARTMENT OF SPEECH COMMUNICATION

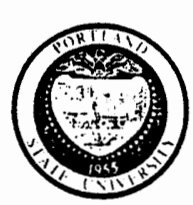

PORTLAND

STATE

UNIVERSITY

P.O. BOX 751

PORTLAND, OREGON

97207

$503 / 229-3531$

April 11, 1985

Dear Study Abroad Program Director,

Enclosed is a copy of a questionnaire I have developed under the direction of Dr. Milton Bennett as a part of a master's degree thesis project I am doing in the department of Speech Communication at Portland State University.

This project has been designed to elicit data on the existing conditions of study abroad programming.

You were selected for this survey through a random sample of the 928 study programs abroad listed in the Institute of International Education's 1984 edition of U.S. College-Sponsored Programs Abroad: Academic Year.

By completing this questionnaire you will be helping us to describe some of the prevailing practices in the study abroad field. This information can help national organizations such as NAFSA and CIEE to gear their programs to the appropriate needs and interests of their members.

We do hope that you will choose to take part in the survey, because complete data from everyone is essential to the usefulness of the study. We assure you complete anonymity. We will not ask you at any point to identify yourself, your program, or your institutional affiliation; the number on the questionnaire is only for follow-up purposes.

We hope that you will take fifteen minutes or so to complete the enclosed questionnaire and return it in the postage-paid envelope. We would be very pleased to send a copy of the results of this study to you as soon as they are available. It would be most helpful if you would include a stamped self-addressed envelope for this purpose.

Please accept our thanks in advance for your assistance with this project. If at all possible please mail the questionnaire to us by April 30,1985 .

Sincerely,

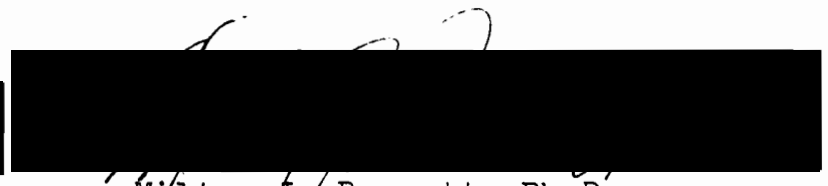


APPENDIX D

RELIABILITY STUDY RESULTS

\begin{tabular}{|c|c|c|c|c|}
\hline $\begin{array}{l}\text { QUES T I } \\
\text { NUMBE }\end{array}$ & & $\mathrm{N}$ & PEARSON & $\begin{array}{l}\text { SI GN I F ICANCE } \\
\text { LEVEL }\end{array}$ \\
\hline I. 2 & & 14 & .68 & $\mathrm{p}<.01$ \\
\hline & & 14 & .84 & $\mathrm{p}<.001$ \\
\hline I. 3 & & 14 & .86 & $\mathrm{p}<.001$ \\
\hline & & 14 & .90 & $\mathrm{p}<.001$ \\
\hline I. 4 & & 11 & .75 & $\mathrm{p}<.01$ \\
\hline & & 11 & .85 & $\mathrm{p}<.001$ \\
\hline I. 5 & & 14 & .90 & $\mathrm{p}<.001$ \\
\hline & & 14 & .77 & $p<.01$ \\
\hline I. $6 \mathrm{~A}$ & & 14 & .77 & $p<.01$ \\
\hline B & & 13 & .93 & $\mathrm{p}<.001$ \\
\hline $\mathrm{C}$ & & 13 & .81 & $\mathrm{P}<.001$ \\
\hline D & & 13 & .95 & $p<.001$ \\
\hline $\mathrm{E}$ & & 13 & .80 & $p<.001$ \\
\hline $\mathrm{F}$ & & 13 & .75 & $\mathrm{p}<.01$ \\
\hline G & & 13 & .66 & $p<.02$ \\
\hline $\mathrm{H}$ & & 13 & .82 & $p<.001$ \\
\hline I & & 13 & .83 & $\mathrm{p}<.001$ \\
\hline $\mathrm{J}$ & & 13 & .49 & $p<.05$ \\
\hline $\mathrm{K}$ & & 13 & .90 & $p<.001$ \\
\hline L & & 13 & .60 & $\mathrm{p}<.05$ \\
\hline M & & 13 & .61 & $p<.05$ \\
\hline $\mathrm{N}$ & & 13 & .48 & $p<.05$ \\
\hline 0 & & 13 & .91 & $\mathrm{p}<.001$ \\
\hline I I . 1 & & 13 & .86 & $\mathrm{p}<.001$ \\
\hline & & 13 & .93 & $\mathrm{p}<.001$ \\
\hline 2 & & 13 & .77 & $\mathrm{p}<.01$ \\
\hline 3 & & 13 & $\begin{array}{r}.86 \\
.88\end{array}$ & $\mathrm{p}<.001$ \\
\hline & & 14 & .80 & $\begin{array}{l}p<.001 \\
p<.001\end{array}$ \\
\hline 4 & & 14 & .97 & $p<.001$ \\
\hline & & 14 & .92 & $\mathrm{p}<.001$ \\
\hline II I. 1 & & 13 & .76 & $\mathrm{p}<.01$ \\
\hline 7 & & 13 & .81 & $\mathrm{p}<.001$ \\
\hline & & 13 & .69 & $\mathrm{p}<.01$ \\
\hline 8 & $\mathrm{CS}$ & 13 & .68 & $p<.01$ \\
\hline & $S \& G$ & 13 & .61 & $\mathrm{p}<.05$ \\
\hline & ETH & 11 & .55 & $p<.10$ \\
\hline & Tof $A$ & 12 & .80 & $\mathrm{p}<.01$ \\
\hline & NRMS & 13 & .74 & $p<.01$ \\
\hline
\end{tabular}




\begin{tabular}{|c|c|c|c|c|}
\hline & $\begin{array}{l}\mathrm{V}, \mathrm{A}, \mathrm{B} \\
\text { CSA } \\
\text { HCC } \\
\text { CR } \\
\text { MC } \\
\text { PRC } \\
\text { L\&F } \\
\text { DIF } \\
\text { C. AD } \\
\text { COP } \\
\text { T.OR } \\
\text { ETH } \\
\text { EMP }\end{array}$ & $\begin{array}{l}13 \\
12 \\
13 \\
11 \\
12 \\
11 \\
13 \\
12 \\
12 \\
13 \\
11 \\
11 \\
13\end{array}$ & $\begin{array}{l}.36 \\
.56 \\
.51 \\
.44 \\
.22 \\
.68 \\
.56 \\
.70 \\
.62 \\
.58 \\
.55 \\
.82 \\
.77\end{array}$ & $\begin{array}{l}\mathrm{p}>.10 \\
\mathrm{p}<.10 \\
\mathrm{p}<.10 \\
\mathrm{p}>.10 \\
\mathrm{p}>.10 \\
\mathrm{p}<.02 \\
\mathrm{p}<.05 \\
\mathrm{p}<.01 \\
\mathrm{p}<.05 \\
\mathrm{p}<.05 \\
\mathrm{p}<.10 \\
\mathrm{p}<.01 \\
\mathrm{p}<.01\end{array}$ \\
\hline 9 & & 13 & .90 & $\mathrm{p}<.001$ \\
\hline IV . 4 & & $\begin{array}{l}14 \\
13\end{array}$ & $\begin{array}{l}.51 \\
.54\end{array}$ & $\begin{array}{l}\mathrm{p}<.10 \\
\mathrm{p}<.10\end{array}$ \\
\hline Section & 1 & 302 & .79 & $\mathrm{p}<.001$ \\
\hline Section & 2 & 108 & .88 & $\mathrm{p}<.001$ \\
\hline Section & 3 & 271 & .69 & $\mathrm{p}<.001$ \\
\hline Section & 4 & 27 & .52 & $\mathrm{p}<.01$ \\
\hline OVER ALL & & 708 & .78 & $p<.001$ \\
\hline
\end{tabular}

